NASA/TM-1998-208662

\title{
Design Selection and Analysis of a Swept and Leaned Stator Concept
}

Edmane Envia

Lewis Research Center, Cleveland, Ohio

M. Nallasamy

NYMA, Inc., Brook Park, Ohio

National Aeronautics and

Space Administration

Lewis Research Center 


\section{Acknowledgments}

The authors wish to thank Mr. Richard P. Woodward and Dr. James E. Bridges, both of the Acoustics Branch at NASA Lewis Research Center, for providing the acoustic data shown in this report and the routines used for computing the 1-foot lossless acoustic power from the measured spectra.

Available from

NASA Center for Aerospace Information

7121 Standard Drive

Hanover, MD 21076

Price Code: A03
National Technical Information Service 5285 Port Royal Road Springfield, VA 22100

Price Code: A03 
1. INTRODUCTION 1

2. SWEEP AND LEAN DESIGN STUDY 1

2.1 Background 1

2.2 Design Tool 2

a) Fan Noise Code 2

b) Fan Wake Description 3

2.3 Design Methodology 3

a) Procedure 3

b) Results 4

c) Selected OGV Design 7

3. ANALYSIS OF SWEPT AND LEANED STATOR 7

3.1 Analysis Tools $\quad 7$

$\begin{array}{ll}3.2 \text { Sideline Directivities } & 8\end{array}$

4. CONCLUSIONS 12

5. ACKNOWLEDGMENTS 13

$\begin{array}{ll}\text { 6. REFERENCES } & 13\end{array}$

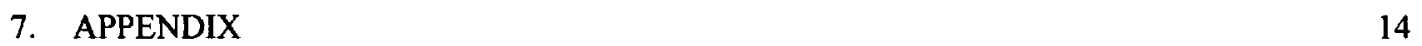




\section{DESIGN SELECTION AND ANALYSIS OF}

\section{A SWEPT AND LEANED STATOR CONCEPT}

\author{
Edmane Envia \\ NASA Lewis Research Center, Cleveland, Ohio
}

\author{
M. Nallasamy \\ NYMA, Inc., Brook Park, Ohio
}

\section{INTRODUCTION}

The commercial air traffic is expected to increase substantially in the coming years, as air travel becomes more affordable worldwide. At the same time, increasingly more stringent community noise regulations will continue to place severe limits on the acceptable levels of aircraft noise near airports. To address these concerns and develop low-noise propulsion technologies, promising concepts for suppression and/or reduction of noise emissions from subsonic aircraft are being investigated under the auspices of NASA Advanced Subsonic Technology (AST) initiative.

The study reported here focuses on the reduction of fan noise which is a significant source of engine noise [Ref. 1]. The targeted source is the so-called rotor-stator interaction tone noise generated as a result of periodic impingement of fan wakes on the outlet guide vanes (OGV). The suppression method involves incorporating swept and leaned stators in the design of the OGV. As shown in Figure 1, sweep is defined as the axial displacement of the vane leading edge from its baseline position. Similarly, lean is defined as the circumferential displacement of the vane leading edge from its baseline position. Since the early ' $70 \mathrm{~s}$, several theoretical and experimental studies have hinted at the potential of sweep and lean for reducing rotor-stator tone noise [Refs. 2-9]. In a more recent experimental study, the benefits of OGV sweep and lean for reducing fan noise were convincingly demonstrated for a representative modern low-speed fan stage [Ref. 10]. The results show that, compared to a radial one, a swept and leaned OGV provides sizable reductions in the level of rotor-stator interaction tone noise for a wide range of operating conditions.

The present report documents the design procedure that was utilized to select the candidate swept and leaned OGV used in that test. The report includes an overview of the theoretical tools used in the study as well as the details of the selection process. The report also contains comparisons of the predicted and measured sideline directivities of the swept and leaned stator against both the baseline radial stator and a swept-only stator. These comparisons serve to validate the design approach and the theoretical tools used in the process. A summary of conclusions drawn from this study is also included.

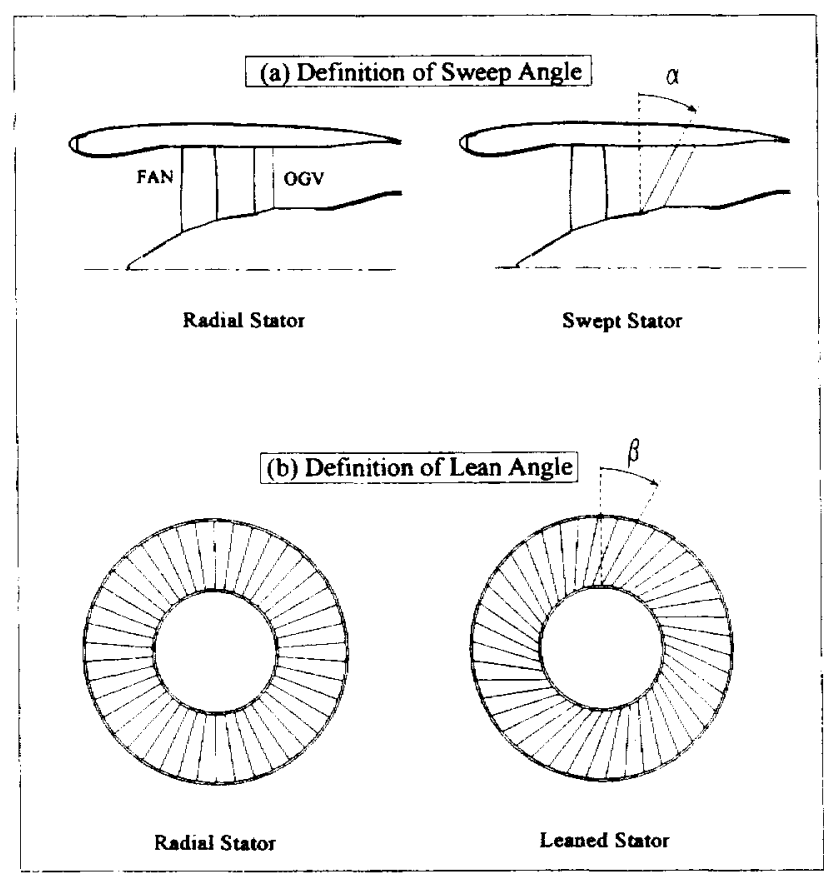

Figure 1. Geometry and definitions of stator vane sweep and lean.

\section{SWEEP AND LEAN DESIGN STUDY}

\subsection{Background}

Rotor-stator interaction noise is caused by the periodic cutting of rotor wakes by the stator vanes. The strength of the interaction is related to the efficiency with which unsteady pressure distribution on the vanes couples to the acoustic modes of the bypass duct [Ref. 11]. The pressure distribution, in turn, depends on the upwash induced by the rotor wake on the stator. It can be shown that, through this dependence, the source strength is strongly influenced by the spanwise phase of the upwash [Ref. 12]. Significant upwash phase variation can cause noise cancellation between contributions from different locations along the vane span resulting in weaker interaction tones. For the most part, variation in the spanwise phase of the upwash is controlled by the number 
of individual rotor wakes that intersect a given vane ${ }^{1}$. This number is determined, primarily, by the kinematics of the rotor wakes in relation to the stator vanes. Swirl variation from hub to tip introduces a tangential shift between the circumferential positions of the wakes along the span. The shift increases with downstream distance causing the tip wakes to advance ahead of the hub wakes. Generally, this shift becomes large enough that wake sheets from more than one blade intersect a single vane.

For a typical fan stage, there usually occur a few intersections per vane. However, for a fixed number of vanes, the introduction of vane sweep and/or lean, changes the number of intersections per vane. The change occurs because sweep and lean alter the kinematic relationship between the wakes and vanes for the same hub-to-tip rotor wake tangential shift. Figure 2 shows the crucial influence
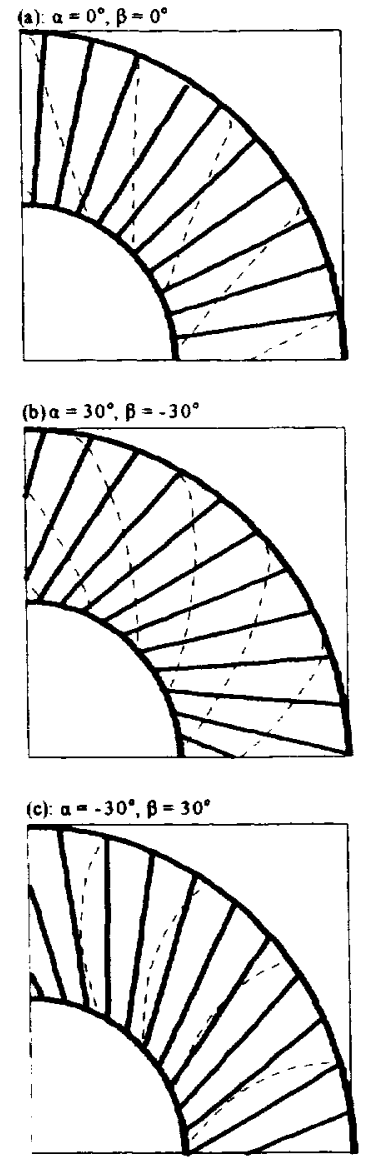

Figure 2. Wake centerline traces (dashed lines) at the stator LE (solid lines). Fan rotates $\mathrm{CW}$. (View looking aft)

of sweep and lean in determining the number of intersections. Sketch (a) in this figure depicts the baseline kinematic picture for a radial stator. Sketches (b) and (c)

${ }^{1}$ Multiple intersections cause the harmonic content of the upwash to experience significant spanwise phase variation. show the change in the relative kinematics for a "beneficial" combination of sweep and lean and a "detrimental" one, respectively. A correct choice of sweep and lean (b) results in additional intersections compared with the radial case, while an incorrect choice (c) reduces the number of intersections. Basically, a beneficial combination increases the streamwise distance between the rotor and the stator allowing more wake tilting to occur. Conversely, an incorrect choice reduces the rotor-stator distance resulting in less tilting before the wake impingement. As will be shown later, the most important message of Figure 2 is that a correct combination of sweep and lean is crucial if maximum noise benefits are to be realized. In fact, an incorrect combination can increase the noise levels. Therefore, the goal of the design procedure was selection of a proper combination of sweep and lean to ensure maximum noise reductions for all operating conditions of interest. For this study, these conditions correspond to the engine power settings for takeoff, cutback and approach.

\subsection{Design Tool}

\section{a) Fan Noise Code}

The theoretical tool used in this study for selecting the candidate low-noise stator is the BBN/V072 fan noise prediction code [Refs. 13-15]. It is based on an analytical nodel for predicting tone levels produced inside the bypass duct due to the interaction of fan wakes with the OGV. The code combines a 2D-strip description of the unsteady aerodynamic interaction between the rotor wakes and stator vanes with a 3D acoustic response of a cascade to an incident gust. The bypass duct is assumed to be a constant-area annulus containing a uniformly moving medium. Both upstream-radiated (inlet) noise and downstrea n-radiated (exhaust) noise are computed by the code.

Noise computations in the BBN/V072 code are done via a two-step process. First, the unsteady surface pressure istribution induced on the vanes by the rotor upwash is determined. Then, the duct noise levels resulting from the unsteady pressure distribution is calculated Following the standard practice, noise results are expressed in terms of the fan blade passing frequency (BPF) to zes. The code provides a mode-by-mode descriptio 1 of the inlet and exhaust noise for each tone. The mode results include cutoff ratio, sound pressure level (SPL), phase, and acoustic power.

The input needed to run the code includes geometric (blade and vane definitions) and fan stage steady aerodynaric performance information. An important element 0 the input information is the definition of viscous wakes of the rotor at the stator leading edge from which 
upwash on the vanes is determined. Wake definition in $\mathrm{BBN} / \mathrm{V} 072$ is based on a set of empirical correlations that are essentially two-dimensional ${ }^{2}$ in nature and, as such, do not fully account for the complex nature of the flow downstream of the fan. This restriction can be avoided if wake data are used to determine the upwash. However, such a description can only be utilized if the following two requirements are met. The first is that data must be taken at the fan operating condition being considered or over a range that brackets the condition of interest. Wake data from operating conditions that are significantly different from the condition of interest can not be used for noise predictions. The second requirement is that the wake measurement station be at or near the stator leading edge. The complicated nature of the flow behind the fan prohibits extrapolation of wake description from the axial station where measurements are taken to another axial location. In the present study wake correlations were used since wake data were unavailable prior to the test.

\section{b) Fan Wake Description}

Wake specification in the BBN/V072 code begins in the rotating (i.e., relative) reference frame. Here, for the sake of developing a mathematically tractable representation, any radial flow that might occur is neglected. Furthermore, the flow is envisaged as a smalldeficit wake profile superimposed on a parallel and locally uniform stream at each radius. Within this framework, the tangential position of the wake centerline at each radius accounts for any wake sheet tilting that might occur due to swirl. In BBN/V072, the tangential position of the wake centerline (at each radius) is determined by the relative flow angle, which is specified as input to the code. The change in the relative flow angle from hub to tip, therefore, represents the tilting of the wake sheet. The introduction of vane sweep and lean can enhance or diminish the wake tilting as seen by the OGV.

As was mentioned earlier, the wake profiles used in the BBN/V072 code are developed from empirical correlations. There are currently two correlation-based wake models in the code that can be used to supply wake centerline velocity deficit and half-width information. The user can choose between the correlations developed by Philbrick and Topol [Ref. 16] or those developed by Majjigi and Gliebe [Ref. 17].

Aside from the wake centerline velocity deficit and half-width, it is also necessary to choose a shape for the rotor wakes. The available choices in the code are a hyperbolic secant profile, a Gaussian profile, and a loaded-

\footnotetext{
2 When using correlations, wake descriptions have an explicit dependence on the axial and tangential coordinates, but depend only parametrically on the radial coordinate.
}

rotor wake profile. In principle, any combination of the correlation parameters and shapes can be used to provide a complete description of wakes. In practice, however, only certain combinations produce reasonable predictions. For this study, the correlations defined in Reference 16 along with the loaded-rotor wake profile were used. The chosen wake characteristics are plotted in non-dimensional form in Figure 3. The decision to use this particular combination was based on experience with similar fan stages.
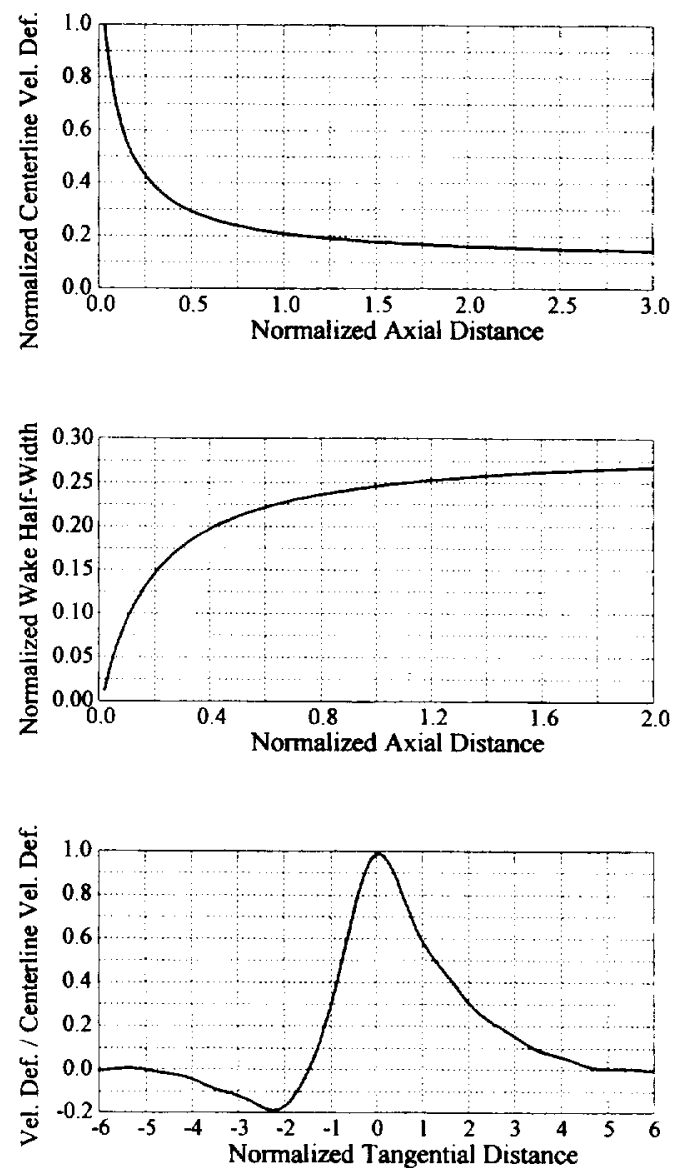

Figure 3. Rotor wake characteristics used in this study.

Once rotor wake characteristics are specified, the resulting description is transformed to the stationary (i.e., absolute) reference frame for computing upwash on the vanes. The upwash is then Fourier decomposed for use in the cascade unsteady pressure calculations. From this information, the BBN/V072 code determines acoustic pressure and power for each of the propagating duct modes.

\subsection{Design Methodology}

\section{a) Procedure}

In this section, we outline the design methodology that was used to identify the optimum vane sweep and lean 
combination. The fan stage considered for this study has 18 blades and 42 radial vanes with a design tip speed of $1,000 \mathrm{fps}$. The fan hub-to-tip radius ratio is 0.3 and that for the stator is 0.5 . The calculations were performed for takeoff ( $84 \%$ of the design tip speed), cutback ( $70 \%$ of the design tip speed), and approach (50\% of the design tip speed). Both upstream- and downstream- radiated noise contributions were considered. Pressure and power levels for all propagating modes contained within the $2 \mathrm{BPF}^{3}$ through 5BPF tones were computed for various combinations of sweep and lean angles. Since, on a modeby-mode basis, the amount of information produced is enormous, it was decided that a global noise metric would be more useful in judging the benefits of sweep and lean. The metric chosen is the change in the computed tone power level from that for the radial stator. With this definition of the metric, a negative change (i.e., reduction) means acoustic benefit. The selection process involves a case-by-case examination of a comprehensive matrix of practical sweep and lean combinations. The acoustic "performance" of each potential configuration is gauged by examining its calculated metric for the selected BPF harmonic at takeoff, cutback and approach. The optimum stator design is one that provides maximum overall tone noise reductions for all operating conditions.

We begin by defining sweep and lean via the two angles shown in Figure 1. Sweep parameter $\alpha$ is defined as the angle, in the meridional plane projection, between the leading edge lines of the straight and swept vanes. Positive sweep is defined as that for which vane tip is downstream of its root. Lean parameter $\beta$ is defined as the angle, in the axial plane projection, between the leading edge lines of the straight and leaned vanes. Positive lean is defined in the direction opposite to rotor rotation. The matrix of the cases used for this study has sweep and lean angles ranging from $-30^{\circ}$ to $30^{\circ}$, in increments of $5^{\circ}$.

\section{b) Results}

In Figures 4 through 9 , the change in acoustic power (i.e., $P(\alpha, \beta)-P(0,0)$ ) as a function of sweep angle is shown for a range of lean angles. In each figure, the results for the $2 \mathrm{BPF}$ through $5 \mathrm{BPF}$ tones are identified. Figures 4 and 5 show the upstream and downstream results for the takeoff condition. Similarly, Figures 6 and 7 correspond to the cutback condition, and Figures 8 and 9 for the approach condition. For the sake of clarity, the levels corresponding to only five lean angles (i.e., $-30^{\circ}$, $-15^{\circ}, 0^{\circ}, 15^{\circ}$, and $30^{\circ}$ ) are plotted. The trends for the intermediate lean angles follow closely those presented here. The results summarized in these figures clearly show that sweep and lean have a significant impact on the predicted tone levels. It is also obvious that the operating
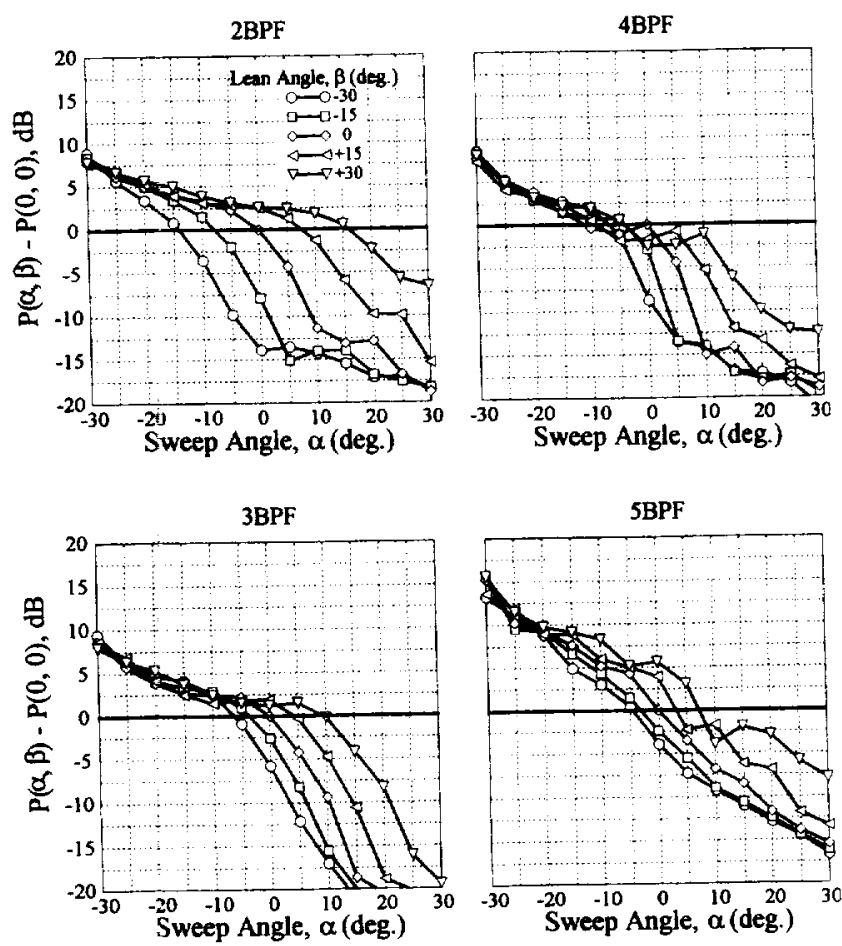

Figure 4. Influence of sweep and lean on the in-duct tone power. Takeoff condition (upstream noise)
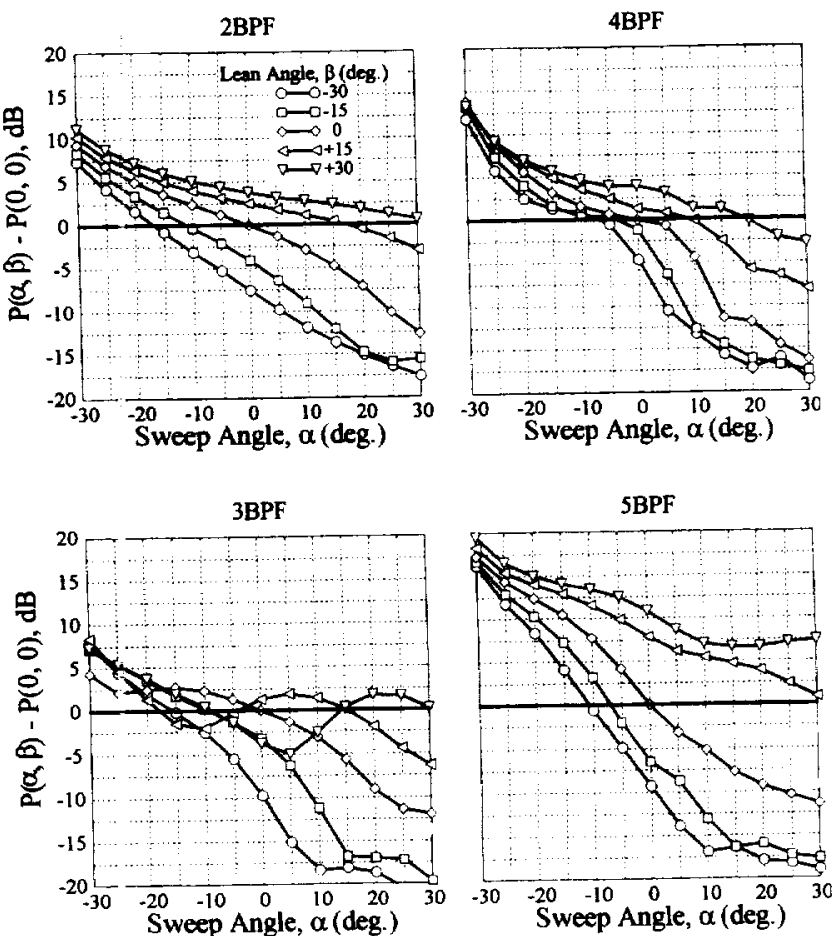

Figure 5. Influence of sweep and lean on the in-duct tone power. Takeoff condition (downstream noise).

\footnotetext{
${ }^{3} \mathrm{BPF}$ is cut-off for this fan stage.
} 

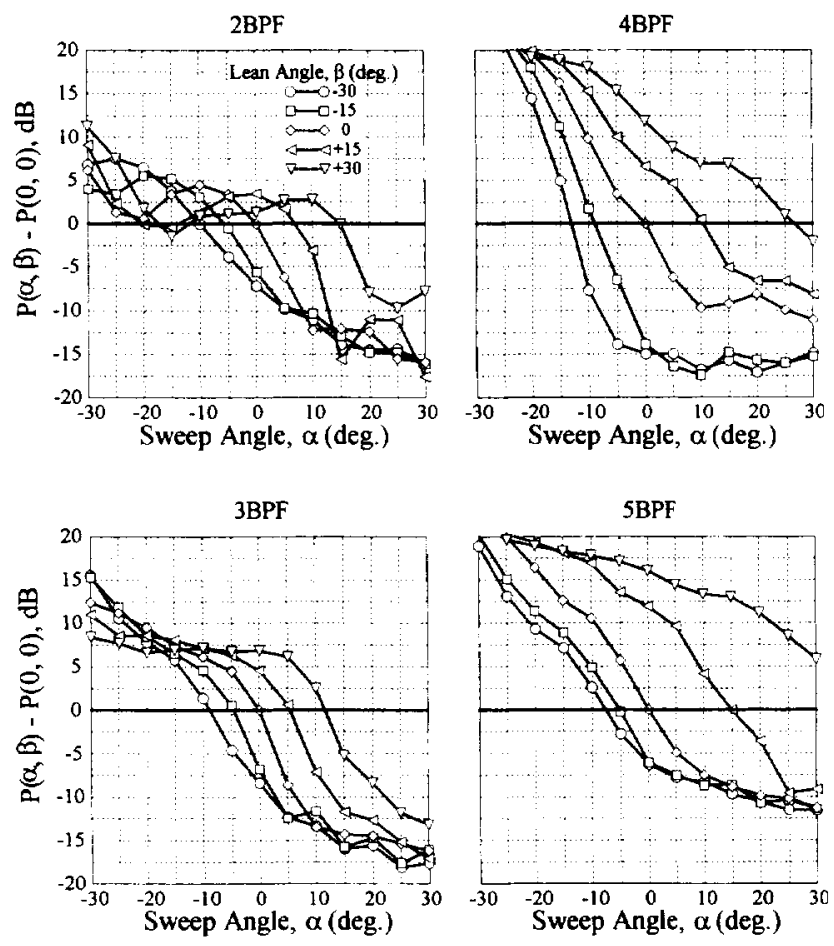

Figure 6. Influence of sweep and lean on the in-duct tone power. Cutback condition (upstream noise).
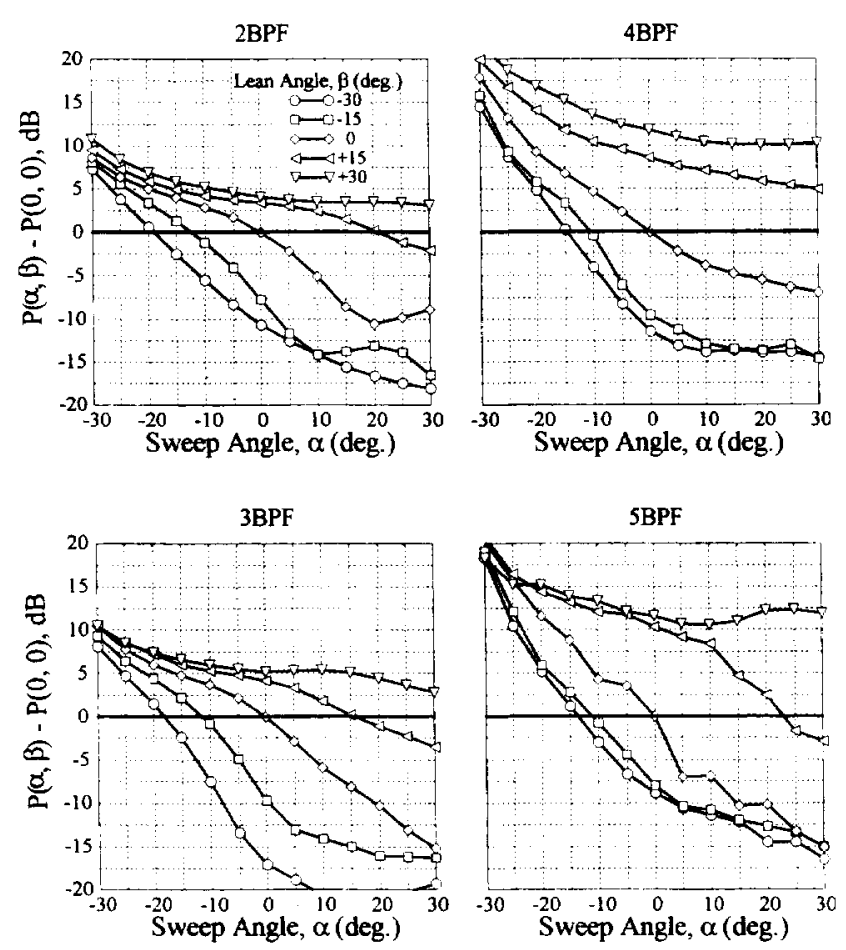

Figure 7. Influence of sweep and lean on the in-duct tone power. Cutback condition (downstream noise).
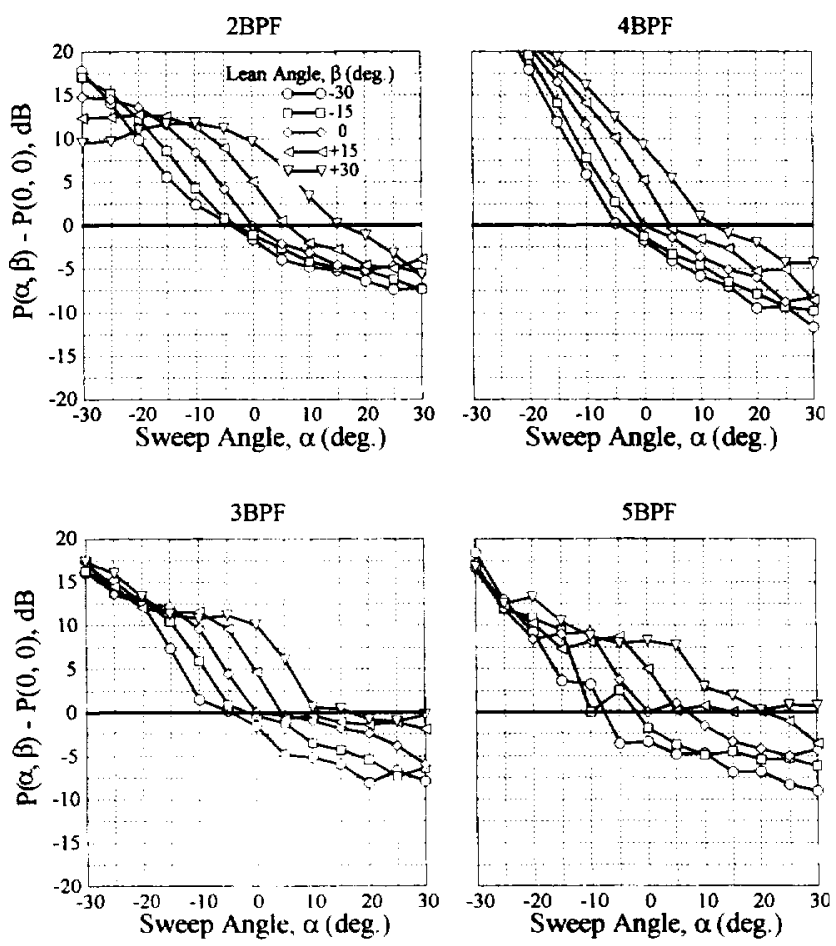

Figure 8. Influence of sweep and lean on the in-duct tone power. Approach condition (upstream noise)
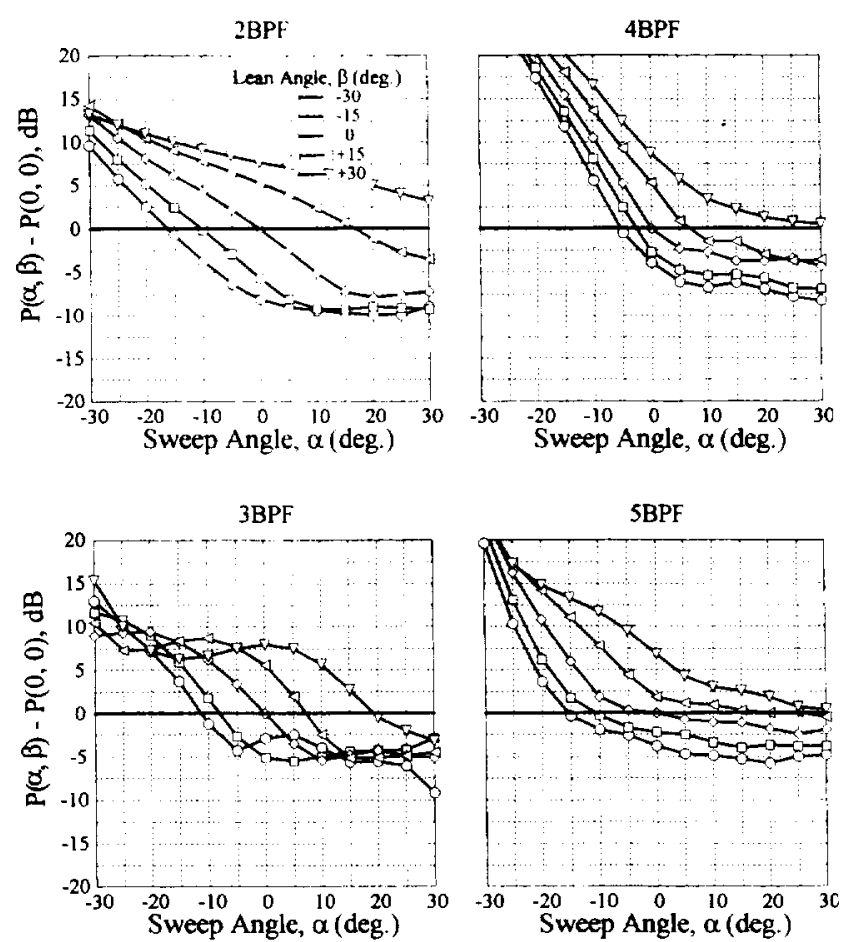

Figure 9. Influence of sweep and lean on the in-duct tone power. Approach condition (downstream noise). 
condition, tone harmonic order, and direction of noise propagation influence the effectiveness of sweep and lean.

Upon a closer examination of these results, the following conclusions can be drawn. Positive sweep angles (i.e., aft sweep) always reduce the tone levels while negative sweep angles increase them. The influence of lean, on the other hand, is more subtle. In most cases, for a given (positive) sweep, negative lean angles (i.e., lean in the direction of fan rotation) enhance the benefits of sweep by causing additional noise reductions. In contrast, positive lean angles tend to diminish, or even offset, the benefits of sweep (see the SBPF plot in Figure 5, for example).

As was stated earlier, the observed behavior with sweep and lean can be explained in terms of their influence on the harmonic phase of the upwash along the vane span. Consider, for example, the predicted noise level changes in the inlet at 2BPF for the takeoff condition (Figure 4). For this condition, consider the beneficial combination of sweep and lean $\left(\alpha=30^{\circ}, \beta=-30^{\circ}\right)$ for which noise is reduced, and the detrimental combination $\left(\alpha=-30^{\circ}, \beta=\right.$ $30^{\circ}$ ) for which noise is increased. In Figure 10, plots of the spanwise harmonic phase variation of the upwash for these three sweep and lean configurations are shown. Note that, compared with the radial stator, the favorable configuration has significantly more spanwise phase variation than the detrimental one. In fact, the latter has less variation compared with the radial stator. It is instructive to compare these phase plots with the kinematic description shown in Figure 2. Compared with the radial stator, the combination $\left(\alpha=30^{\circ}, \beta=-30^{\circ}\right)$ allows for more wake-vane intersections and, therefore, more spanwise phase variation. Conversely, for the combination $\left(\alpha=-30^{\circ}\right.$, $\beta=30^{\circ}$ ) fewer intersections lead to less phase variation.

Now let's examine the impact of the upwash phase variation on the predicted vane unsteady surface pressure distribution. In Figure 11, phase contours of the unsteady surface pressure corresponding to the three sweep and lean combinations of Figure 10 are shown. Compared with the radial stator, the correct choice of sweep and lean produces significantly more variation in the phase of surface pressure. In contrast, the incorrect choice actually reduces the phase variation. Now, since the tone levels are related to the surface integrals of the vane unsteady pressure, the more phase variation there is in the unsteady pressure, the more cancellations will occur in these integrals resulting in weaker tones as seen in Figure 4 for the combination $\left(\alpha=30^{\circ}, \beta=-30^{\circ}\right)$. On the other hand, if there is less phase variation, there will be less cancellation leading to higher tone levels as seen for the combination $\left(\alpha=-30^{\circ}, \beta=30^{\circ}\right)$. These plots corroborate the argument that was advanced in section 2.1 regarding the role of (a): $\alpha=0^{\circ}, \beta=0^{\circ}$

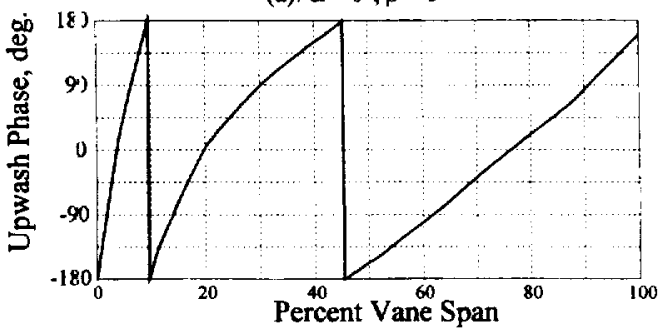

(b): $\alpha=30^{\circ}, \beta=-30^{\circ}$

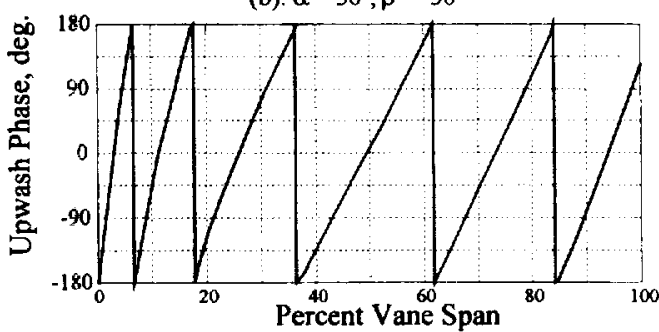

(c): $\alpha=-30^{\circ}, \beta=30^{\circ}$

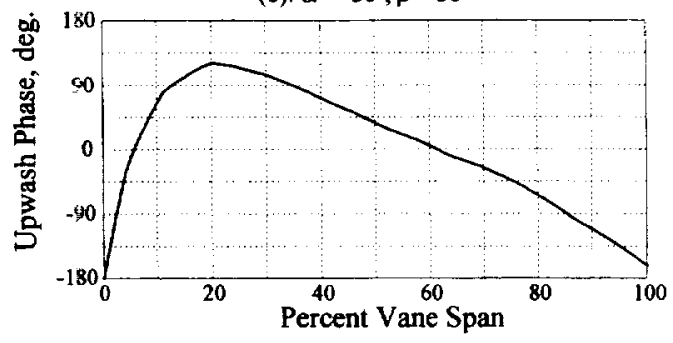

Figure 10. Spanwise phase of the 2BPF component of the upwash at the takeoff condition.
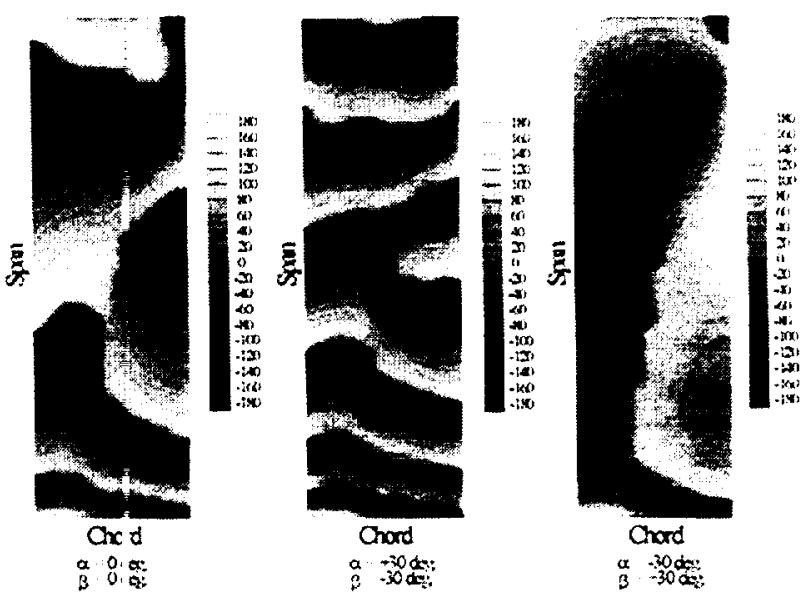

Figure 11. Phase contours of vane unsteady surface pressure (theory). Vane planform is mapped to a rectangle to facilitate comparisons.

sweep and lean in changing the tilt of the rotor wakes relative $t o$ the stator vanes. They also clearly demonstrate the impcrtance of the proper choice of sweep and lean combination. Of course, as was stated earlier, the realized 
sweep and/or lean benefits vary with fan tip speed and tone harmonic order. In general, the predicted noise reductions tend to be more significant at higher tip speeds and for higher tone harmonics. Both of these observations are consistent with the kinematic argument. The tip speed trend is justifiable because over the same streamwise distance the higher fan tip speed at takeoff produces more wake tilting than does the lower tip speed at approach. Similarly, the benefits are larger for higher tone harmonics, because harmonic phase variation is directly proportional to the harmonic order whether or not there is sweep and/or lean. So, for example, if there are three sign changes in the spanwise phase for the $2 \mathrm{BPF}$ tone there will be twice as many for the $4 B P F$ tone and so on.

\section{c) Selected OGV Design}

The theoretical results presented above indicate that, to reduce rotor-stator interaction tone noise, stator vanes should have aft sweep and should be leaned in the direction of fan rotation. Furthermore, they also suggest that there are more acoustic benefits for larger sweep and lean angles. Therefore, it was decided to implement the largest sweep and lean angles that were structurally and aerodynamically feasible. These requirements resulted in a swept and leaned vane design having $30^{\circ}$ of aft sweep (i.e., $\alpha=30^{\circ}$ ) and $30^{\circ}$ of lean in the direction of fan rotation (i.e., $\beta=-30^{\circ}$ ). To separate the benefits of sweep and lean, a swept-only stator (i.e., $\alpha=30^{\circ}, \beta=0^{\circ}$ ) was also selected. Photographs of the fan stage assembly ${ }^{4}$ with the swept-only and swept and leaned stators are shown in Figure 12.

The selected stator configurations were tested ${ }^{5}$ in the NASA Lewis 9' $\times 15^{\prime}$ Acoustic Wind Tunnel where detailed farfield noise measurements were obtained at several fan operating conditions. The data unequivocally show that, compared to the radial OGV, the swept and leaned OGV is quieter at all tested conditions. The sweptonly stator also shows sizeable acoustic benefits. Later in this report detailed comparisons between the measured and predicted sideline directivities of the radial, swept-only, and swept and leaned stators will be presented.

\footnotetext{
${ }^{4}$ The Allison Engine Company, under contract to NASA Lewis Research Center, built the fan stage and the tested stator configurations [Ref. 18]

5 The baseline radial stator was tested in two axial positions, a "forward" position and an "aft" position. The forward position corresponds to the hub axial location of the swept/leaned stators. The aft position corresponds to the tip axial location of the swept/leaned stators. This was done to separate the noise reduction due to sweep-induced phase cancellation from the noise reduction due to the increased axial spacing for the swept/leaned stators compared with the radial stator. In this report, the results for the radial stator in the aft position are not considered.
}
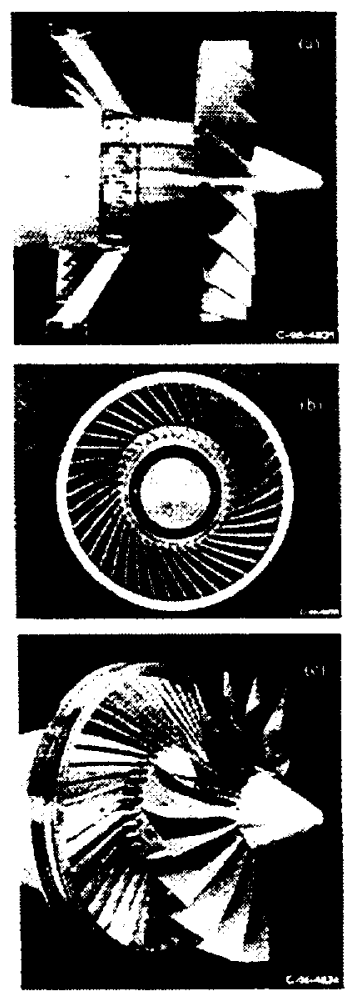

Figure 12. Photographs of the partially assembled fan stages. (a) is the side view of the swept stator and (b) and (c) are different views of the swept and leaned stator.

\section{ANALYSIS OF THE SWEPT AND LEANED STATOR}

\subsection{Analysis Tools}

The predicted sideline directivities are calculated using two codes designed to predict the farfield tone noise radiation from inlet and exhaust sections of a fan bypass duct. As shown in Figure 13, the inlet and exhaust codes compute the radiation fields in the forward and aft arcs, respectively. In each case, the arc covers a region extending from the fan axis to a location past the $90^{\circ}$ position. In the overlap region the linear nature of the wave equation permits the addition of the two solutions (with the phase taken into account) to obtain the complete sideline directivity.

Both of these codes are based on a frequencydomain finite element formulation of the problem of acoustic radiation from termination of an axisymmetric duct [Refs. 19 and 20]. They solve for the acoustic field (both inside and outside of the duct) once the internal geometry of the duct and the in-duct pressure are specified. The specification of the internal acoustic field is in terms of amplitudes of the cut-on duct modes at the internal boundary of the computational domain. The mode input 


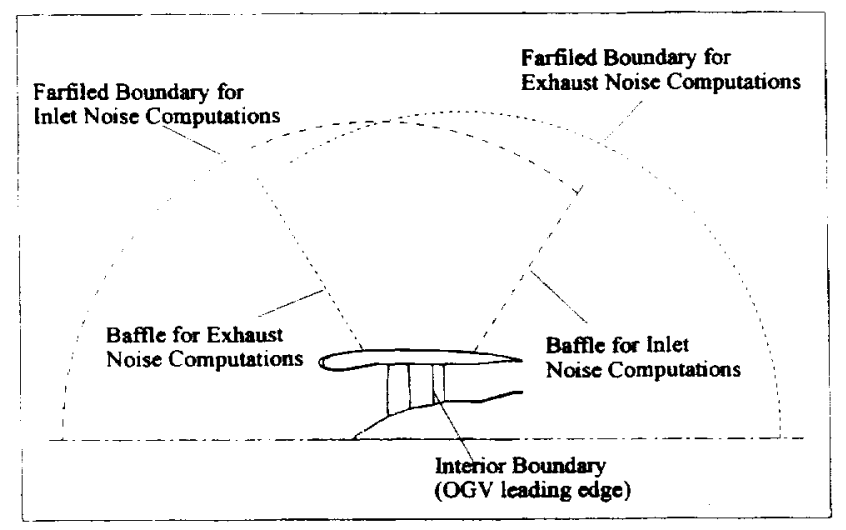

Figure 13. Computational domains for inlet and exhaust computations.

can be supplied from in-duct measurements or from predictions (from the BBN/V072 code, for example). The duct internal and external flowfields are assumed to be irrotational and are calculated as part of the solution. The computational domain for each code is the region that starts at the input plane inside the duct and extends outside of the duct between the fan axis and a suitably chosen "baffle" (see Figure 13). The baffle is a pressure release boundary that permits outgoing waves only. Both lined (i.e., absorbent) and unlined (i.e., hard) boundary conditions can be specified on the duct walls and a Sommerfeld radiation condition is applied on the farfield arcs and the baffles.

For the exhaust problem, the presence of the exhaust jet shear layer requires implementation of additional constraints in the calculations. For the mean flow, since the dynamics of the shear layer is highly complicated, a simplified condition is implemented. The layer is modeled as though the bypass duct extends some distance downstream of the exit plane. Therefore, in the extended region the flow is composed of two parts, an inner flow and an outer flow, and the velocity potential is discontinuous across the layer. But, beyond this extended region, the velocity potential is assumed to be continuous and the internal and external flows are permitted to mix on a potential flow basis. The extent of the "fictitious duct" is chosen so as to provide realistic acoustic wave diffraction effects across the shear layer while at the same time minimize the influence of the artificial mixing on the acoustic field (see Reference 20). This treatment of the shear layer is found to work reasonably well for the moderate flow Mach numbers considered in this report. For the acoustic calculations, the presence of the shear layer necessitates the specification of two continuity conditions along the interface. These are the continuity of acoustic pressure across the shear layer, and the continuity of displacement of the interface itself. The latter is a kinematic condition arising from the assumption that the interface acts as an impermeable membrane across which acoustic perturbations are transmitted by virtue of its motion.

Recent applications of this type of an approach to the prediction of farfield fan noise may be found in [Refs. 21-24]. In the present study, using mode predictions from the BBN/V072 code as input for the radiation codes, sideline directivities for the radial, swept-only and swept and leaned stators were computed and compared with the measured data. The comparisons were carried out for the 2BPF tone at the approach, cutback and takeoff conditions and for the 3BPF tone at the approach condition only. The sideline, where noise data were taken, is $\mathbf{8 8}$ " away from the fan axis. The tunnel Mach Number is 0.1 chosen to guarantee that the background tunnel noise level was well below the noise from the fan model [Ref. 25].

\subsection{Sideline Directivities}

We begin the data-theory comparisons with the radial stator whose results are shown in Figure 14. The figure shows plots of 2BPF tone SPL as a function of the emission angle for each speed considered in this report. The symbols represent the measurements and the solid curves the predictions. The thin line connecting the data points is drawn to aid in discerning the pattern of the measured directivities. To help analyze the trends, the measured broadband noise level at 2BPF is also shown (dashed line). The SPL range for each graph is chosen so as to provide the best overall representation of the results but the increment is kept the same for all graphs to allow for easy comparison.

The radial OGV results show that there is generally a good agreement between the predicted and measured directivities for the approach and cutback conditions, but that the agreement is only marginal for the takeoff :ondition. In particular, at approach the predicted peak Sl'L and peak radiation angles for both inlet and exhaust are well predicted. In fact, over the entire range of emission angles, the predicted directivity is close to the measured one. On the other hand, the data-theory agreement for takeoff is rather poor. For this speed, there are significant over-predictions in both the inlet and exhaust portions of the directivity. For the cutback conditic $n$, there is fair agreement in the inlet but significant over-prediction in the exhaust. It should be noted that where the measured tone is very close to the broadband level, the tone data is not entirely reliable. By the same token, the sharp dips in the predicted directivities are somewhat unrealistic and should be "clipped" with the broadband level. It is these clipped predictions that should 

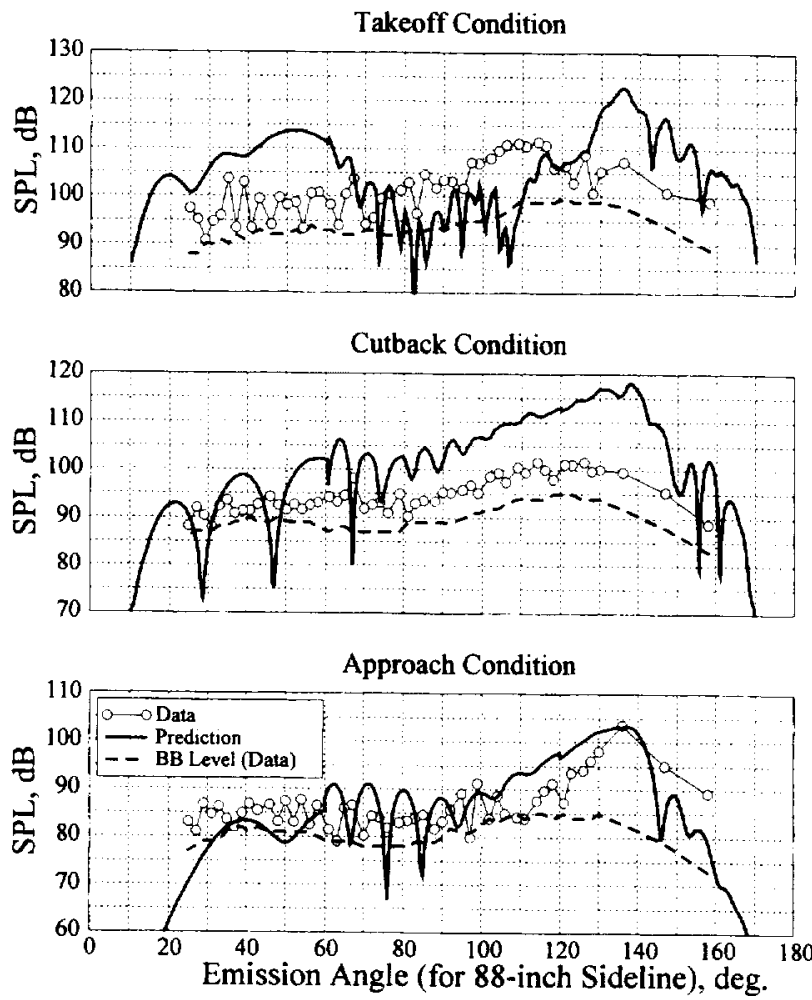

Figure 14. Comparison of measured and predicted 2BPF tone farfield directivities for the radial stator. Measured broadband noise level at 2BPF tone is also shown.

be compared with the measured tone levels. With that in mind, the data-theory comparisons are improved, particularly, for the approach condition. Overall, given the simplifications made in modeling the noise source and, to a lesser extent, those employed in the radiation predictions, the overall data-theory agreement (at both speeds) is very encouraging.

The results for the swept-only stator are summarized in Figure 15. For this configuration, the absolute 2BPF levels are significantly lower than those for the radial stator and so they are closer to the broadband noise levels. Overall, the data-theory agreement is remarkably good. Here the trends, as well as the levels, are well predicted for all three speeds. There are, nonetheless, local discrepancies especially for the cutback and takeoff conditions for which the theory over-predicts the measured exhaust SPL at large emission angles. Note that both the measured and predicted levels for the swept-only stator show sizable reductions compared to the levels for the radial stator levels as discussed below.

Predicted and measured 2BPF tone reductions due to sweep (i.e., swept-only OGV levels minus radial OGV levels) are shown in Figure 16. Note that with this definition, the $0 \mathrm{~dB}$ represents the level for the radial
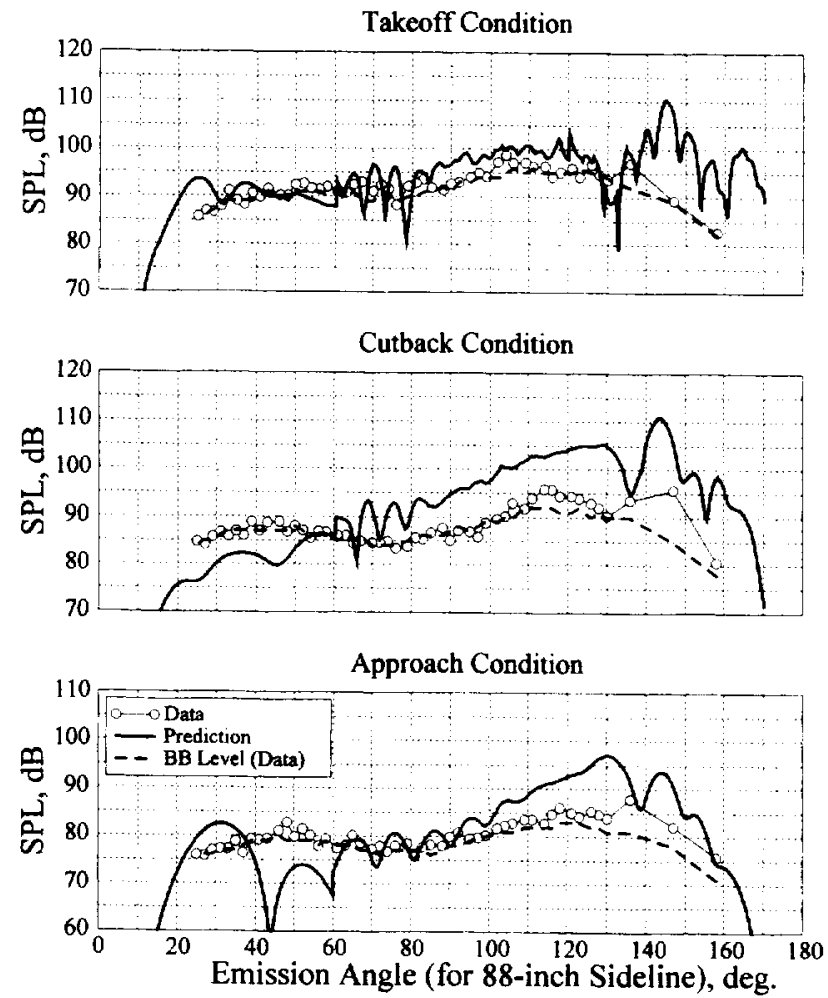

Figure 15. Comparison of measured and predicted 2BPF tone farfield directivities for the swept stator. Measured broadband noise level at $2 \mathrm{BPF}$ tone is also shown.

stator. The symbols now indicate the measured tone reductions and the solid line the predicted reductions. Here, the dashed lines represent broadband-corrected predictions calculated using the clipped predictions that were discussed earlier. The measured benefits, while not uniform, are generally centered on the $5 \mathrm{~dB}$ level for the approach condition, around the $7.5 \mathrm{~dB}$ levels for the cutback condition, and on the $10 \mathrm{~dB}$ level for the takeoff condition. As for the predictions, at approach and cutback the bulk of the noise reductions fall in the $5-10 \mathrm{~dB}$ range especially when the broadband-corrected levels are considered. For takeoff, the predicted reductions are somewhat larger and more erratic. This is, of course, the result of the fact that the predicted radial stator levels do not agree well with the data even though the levels for the swept-only stator do. Nevertheless, the general trend of reductions with the fan tip speed is reasonably well predicted in the sense that the reductions are higher at takeoff compared to those for approach.

Next, the comparisons for the swept and leaned stator (i.e., $\alpha=30^{\circ}, \beta=-30^{\circ}$ ) are shown in Figure 17. Note that for this configuration, the absolute levels for the 2BPF tone are essentially at the broadband level. This suggests that the sharp oscillations in the predicted levels should be ignored when comparing the theoretical and experimental 

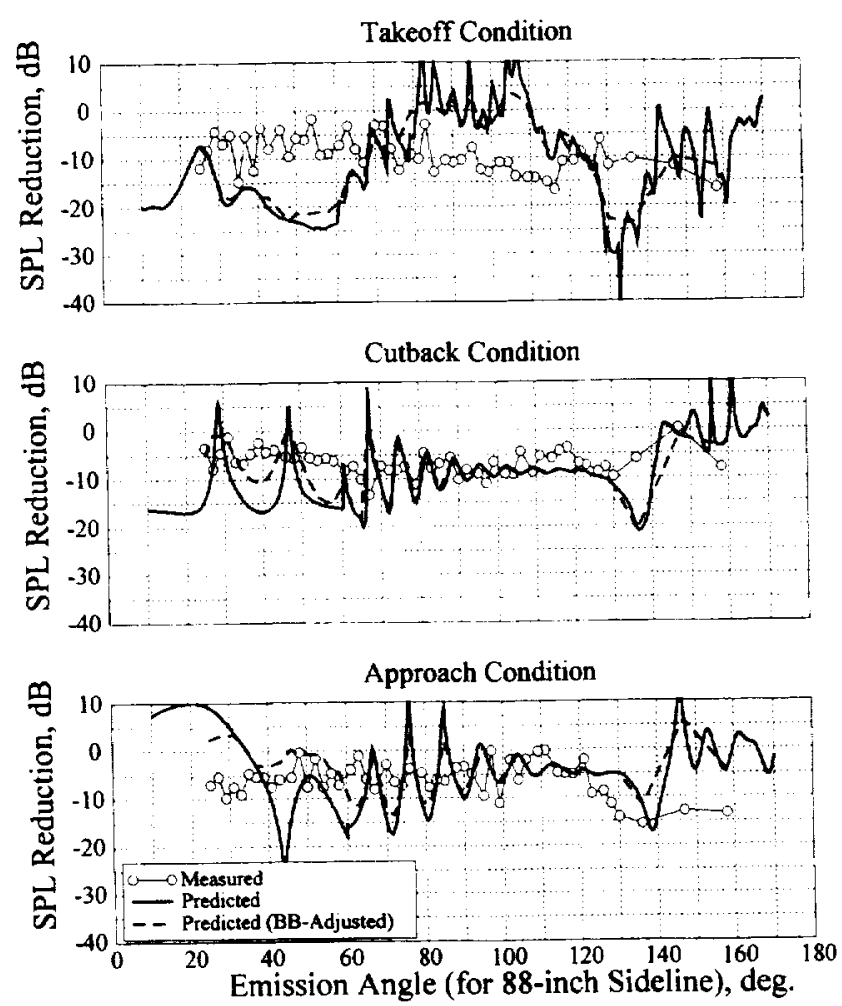

Figure 16. Comparison of measured and predicted 2BPF tone reductions in the farfield due to sweep (radial stator is the baseline). Broadband-corrected predicted reductions are also shown.

results. With that in mind, the general agreement between the data and theory is very good for this configuration with the measured SPL's being very close to the average predicted reductions for all three speeds.

Figure 18 shows the $2 \mathrm{BPF}$ tone SPL reductions when the radial stator levels are used as the baseline. If the broadband-corrected predictions are used, the predicted reductions compare quite well with the measured reductions for approach and cutback, but the comparison is poor at takeoff. The agreement for the takeoff condition is poor because the directivity for the radial stator is not well predicted. The measured reductions are about 5 to $7 \mathrm{~dB}$ for approach and cutback and around $10 \mathrm{~dB}$ for takeoff. The predicted reductions are somewhat higher for all three speeds. The tone reductions summarized in figures 16 and 18 clearly demonstrate the success of sweep and lean in reducing the tone level.

To assess the benefits of swept and leaned stator versus the swept-only stator, the 2BPF tone SPL difference between the two configurations is plotted in Figure 19. Note that, the $0 \mathrm{~dB}$ now represent the level due to the swept-only' stator. The calculated differences in the measured tone levels are generally centered on the $0 \mathrm{~dB}$
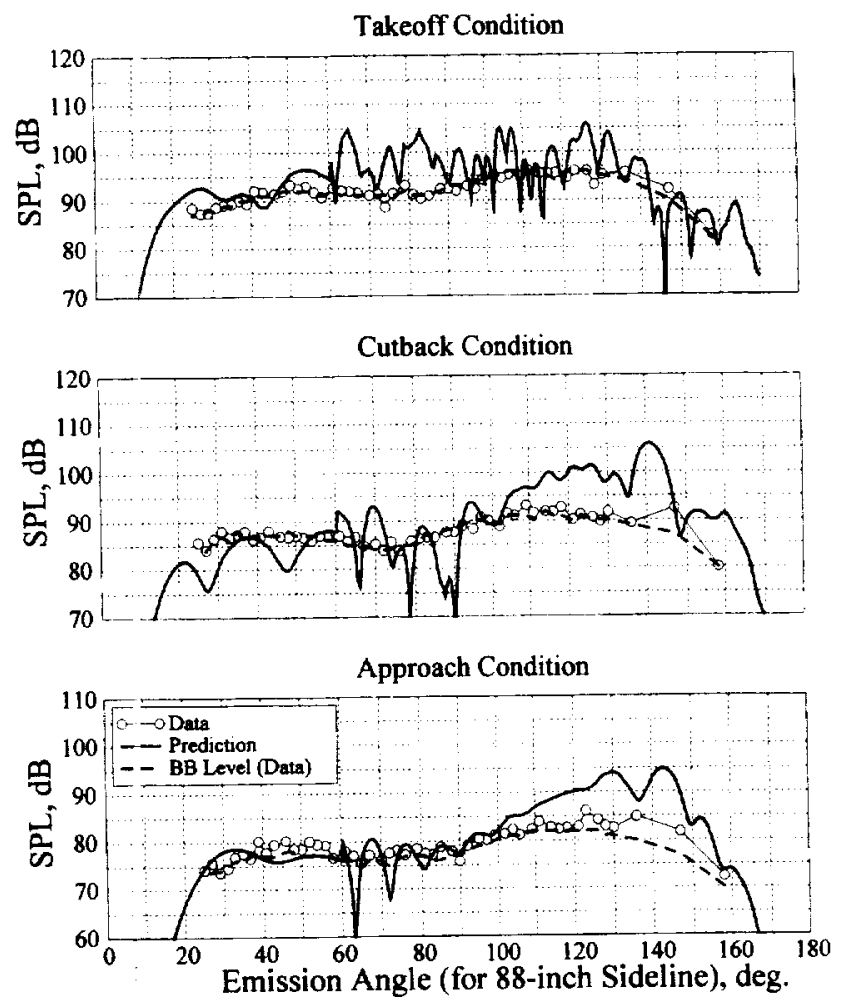

Figure 17. Comparison of measured and predicted 2BPF tone farfield directivities for the swept and leaned stator. Measured broadband noise level around 2BPF tone is also shown.

level with noticeable additional benefits only in the exhaust region. This suggests that the swept and leaned stator is not significantly quieter than the swept-only stator except in the exhaust. The corresponding predicted differences generally show quite a good agreement for most of the emission angles at all speed conditions, especially when the broadband-corrected predictions are used for calculating the reductions (dashed lines). The exceptions are the predicted benefits for the exhaust emission angles greater than $140^{\circ}$ for the cutback and takeoff conditions where the theory predicts significant additional benefits for the swept and leaned OGV compared with the swept-only OGV.

A tacit assumption used in computing the farfield directivities presented in this report is that the rotor transmission losses are negligible. Despite this approx mation, however, the general agreement between the pre licted and measured noise reductions is remarkably good. A possible explanation for this agreement is that the 2BPF one does not suffer significant transmission losses through the rotor for this fan. It is also possible that the rotor affects the absolute levels of the $2 \mathrm{BPF}$ tone equally for all three stators, so that it drops out of the difference calculitions. However, given that with the exception of the 

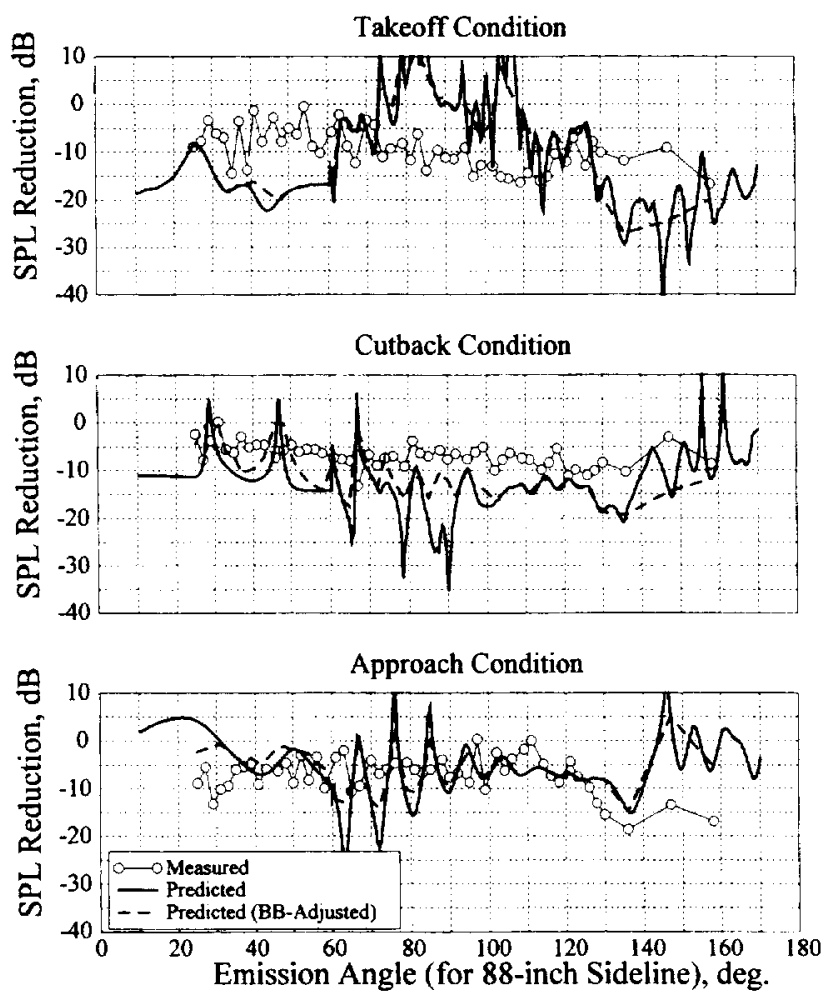

Figure 18. Comparison of measured and predicted 2BPF tone reductions in the farfield due to sweep and lean (radial stator is the baseline). Broadband-corrected predicted reductions are also shown.

radial stator at the takeoff condition the directivities for all other speeds and configurations are in very good agreement with the data, the first explanation seems more likely.

Returning to the data-theory comparisons, we next present the results for the $3 B P F$ tone for which the predictions are restricted to the approach condition only. The sideline directivities for cutback and takeoff could not be obtained because the mesh resolution requirements for the frequencies corresponding to these conditions are beyond the current capabilities of the two radiation codes. The format of the subsequent presentation is therefore slightly different from the results presented so far.

In Figure 20 measured and predicted 3BPF tone sideline directivities are shown. From the top, the graphs are for the radial, swept-only and swept and leaned stators. The symbols indicate data and the solid lines represent the predictions. The measured broadband noise level at $3 \mathrm{BPF}$ is also shown for each stator (the dashed line). The results indicate that while there is a reasonably good agreement between the data and theory in the inlet region, there are noticeable under-predictions in the aft region. The magnitude of the under-prediction depends on the stator
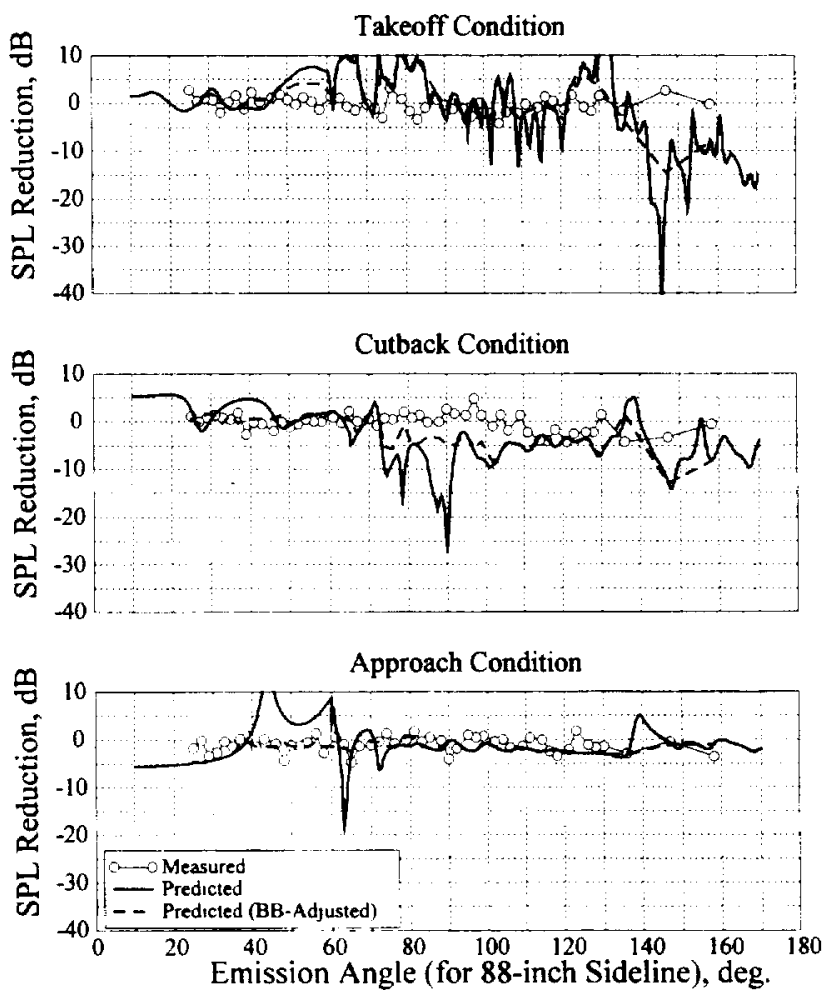

Figure 19. Comparison of measured and predicted 2BPF tone reductions in the farfield due to sweep and lean (swept stator is the baseline). Broadband-corrected predicled reductions are also shown.

configuration. For the radial and swept-only stators the discrepancies are modest (around $5 \mathrm{~dB}$ ), but for the swept and leaned case they are as much as $10 \mathrm{~dB}$. However, it should be noted that, except for the radial case, for which there is noticeable tone protrusion, the levels of measured tone and broadband are virtually equal for the 3BPF tone. Therefore, a better data-theory comparison is obtained when the broadband levels are taken into account in assessing the predicted noise benefits. In that case, the predictions agree rather well with the measured benefits.

In Figure 21, measured and predicted SPL reductions due to sweep-only and sweep and lean are presented. From the top, the graphs show the noise benefits of a swept-only stator compared with the radial stator (i.e., $p(30,0)-p(0,0)$ ), the benefits of the swept and leaned stator compared with the radial stator (i.e., $p(30$, $30)-p(0,0)$ ), and the benefits of the swept and leaned stator compared with the swept-only stator (i.e., $p(30,-30)$ - $p(30,0))$. Overall, the comparison between the measured reductions (symbols) and the predicted reductions (solid lines) is quite reasonable, especially when the broadbandcorrected predictions are used for computing the predicted benefits (dashed lines). Similar to the 2BPF tone, there are measurable noise benefits when the OGV is swept or is 

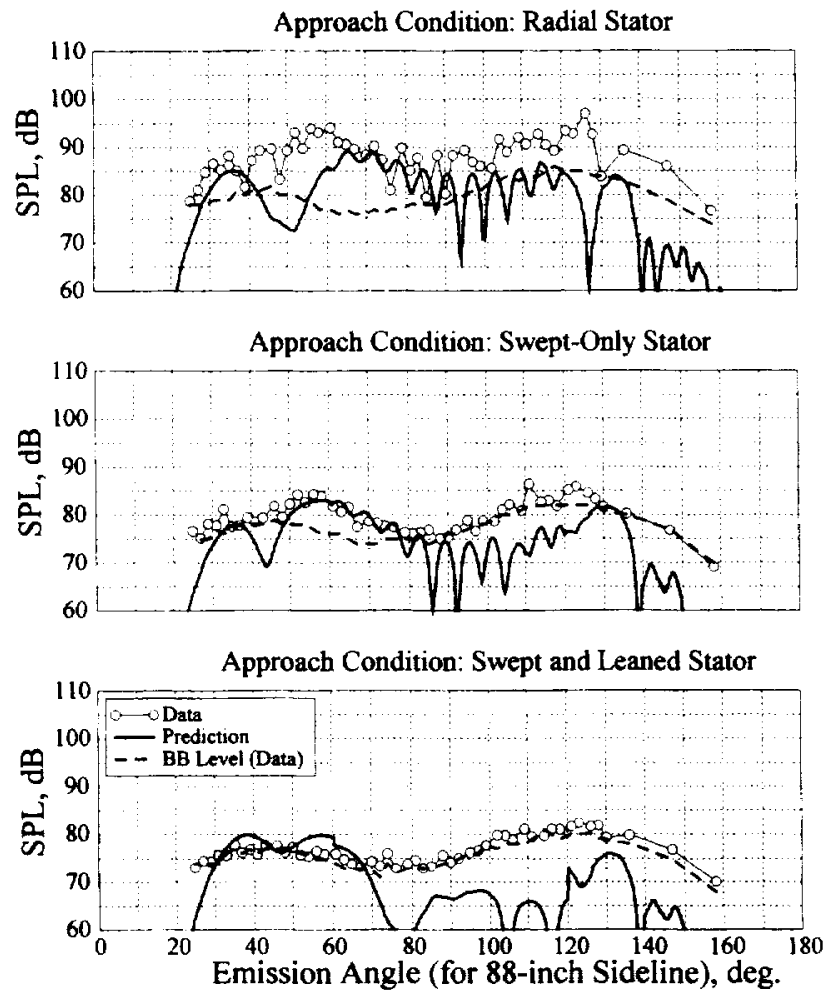

Figure 20. Comparison of measured and predicted 3BPF tone farfield directivities for the radial, swept-only, and swept and leaned stators at approach condition. Measured broadband noise level around 3BPF tone is also shown.

swept and leaned in accordance with the noise reductions shown in Figures 8 and 9.

Since a direct data-theory SPL comparison for higher tip speeds (or, for that matter, higher harmonics) could not be made, an indirect method was employed. The procedure involves comparing the in-duct acoustic power levels computed in Section 2 of this report with acoustic power level estimates based on integrating the measured sideline SPL's for the higher speeds and/or tones. The estimates are based on 1-foot lossless tone data computed from the measured spectra at the 88-inch sideline. For the sake of consistency and completeness, these comparisons have been carried out at all three speeds and for all the harmonic tones between 2BPF and 5BPF. Using the same procedure, the corresponding broadband noise level in the neighborhood of each tone was also calculated to help with the analysis of the tone data.

The salient conclusion from these comparisons is that the broadband-corrected duct power level predictions agree remarkably well with the power levels calculated from the measured sideline directivities. This is true both of the absolute levels of the acoustic power in the individual tones as well as the variations of tone power
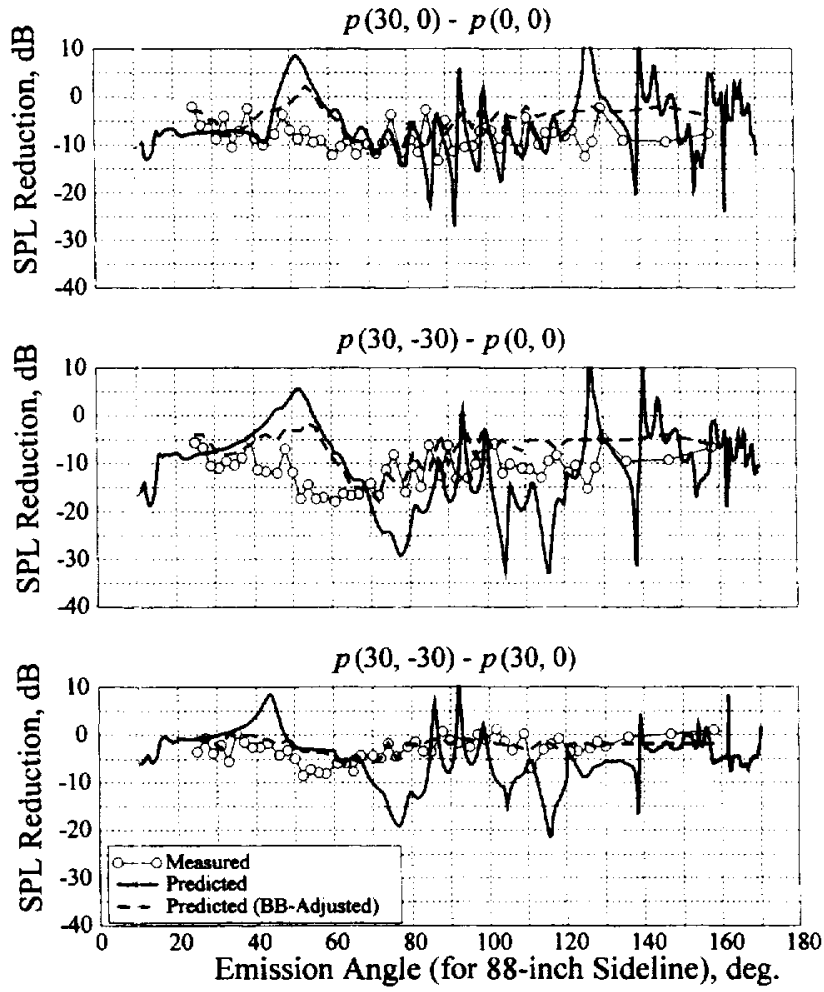

Figure 21. Comparison of measured and predicted 3BPF tone reductions in the farfield; top figure shows the sweep benefits directivities for the radial, swept-only, and swept and leaned stators. Broadband-corrected predicted reductions are also shown.

levels with sweep and lean. The complete set of datatheory comparison plots for tone power levels is included in the Appendix.

\section{CONCLUSIONS}

The principal conclusion of this study is that, when chssen properly, sweep and/or lean reduce rotorstator in eraction tone noise. Using a set of inlet and exhaust radiation codes to establish a link between the predicted in-duct pressure levels and the farfield noise levels, the theoretical sideline directivities were shown to be consistent with the experimental data. A kinematic argumen: was proposed to explain the mechanism of noise reduction I due to sweep and lean. This argument suggests that to $r$ educe noise, sweep and lean must be chosen in such a way so as to increase wake intersections per vane. A set of simple design rules is proposed for implementing sweep and lean in practical fan stage geometries. Sweep for which the vane tip is downstream of its root, and lean in the direction of the fan rotation reduce the strength of the interaction tones with size of reduction dependent on the amount of sweep and lean chosen. 
A secondary conclusion is that the codes used in this work provide reasonably accurate tools for studying the aeroacoustics performance of modern fan stages. It should be emphasized that all of the theoretical results shown here were plotted without any adjustments or shifts in their levels and as such they represent true predictions. While the task of accurately calculating the absolute noise levels for all emission angles at all relevant fan operating conditions and stator configurations remains a challenge, the essential features of the sideline directivity, as well as the trends associated with sweep and lean, are accurately captured with the codes used in this study. Improvements in noise source modeling cannot but help improve these predictions further.

\section{ACKNOWLEDGEMENTS}

The authors wish to thank Mr. Richard $\mathrm{P}$. Woodward and Dr. James E. Bridges, both of the Acoustics Branch at NASA Lewis Research Center, for providing the acoustic data shown in this report and the routines used for computing the 1-foot lossless acoustic power from the measured spectra.

\section{REFERENCES}

1. Groeneweg, J.F. and Rice, E.J., "Aircraft Turbofan Noise," Transactions of the ASME, 109, pp. 130-141, 1987.

2. Rao, G.V.R., "Use of Leaning Vanes for Fan Noise Reduction," AIAA Paper 72-126, January 1972.

3. Kazin, S.B., "Radially Leaned Outlet Guide Vanes for Fan Source Noise Reduction," NASA-CR 134486, November 1973.

4. Adamczyk, J.J., "Passage of a Swept Airfoil Through an Oblique Gust," Journal of Aircraft, Vol. 11, 1974, pp. 281-287.

5. Hayden, R.E., Bliss, D.B., Murray, B.S., Chandiramani, K.L., Smullin, J.I., and Schwaar, P.G., "Analysis and Design of a High Speed, Low Noise Aircraft Fan Incorporating Swept Leading Edge Rotor and Stator Blades," NASA CR-135092, December 1977.

6. Schulten, J.B.H.M., "Sound Generated by Rotor Wakes Interacting with a Leaned Vane Stator," AIAA Journal, Vol. 20, No. 10, 1982, pp. 1352-1358.
7. Envia, E. and Kerschen, E.J., "Noise Produced by the Interaction of a Rotor Wake with a Swept Stator Blade," AIAA Paper 84-2326, October 1984.

8. Envia, E. and Kerschen, E.J., "Noise Generated by Convected Gusts Interacting with Swept Airfoil Cascades," AIAA Paper 86-1872, July 1986.

9. Envia, E. and Kerschen, E.J., "Influence of Vane Sweep on Rotor-Stator Interaction Noise," NASA-CR 187052, December 1990.

10. Woodward, R.P., Elliott D.M., Hughes, C.E., and Berton, J.J., "Benefits of Swept and Leaned Stators for Fan Noise Reduction," NASA-TM (TBD), October 1997.

11. Groeneweg, J.F. and Sofrin, T.G., Gliebe, P.R., and Rice, E.J., "Turbomachinery Noise," in Aeroacoustics of Flight Vehicles: Theory and Practice, Volume 1: Noise Sources, Edited by H.H. Hubbard, NASA RP1258, Vol. I WRDC Technical Report 90-3052, August 1991.

12. Envia, E., Huff, D.L., and Morrison, C.R., "Analytical Assessment of Stator Sweep and Lean in Reducing Rotor-Stator Tone Noise," AIAA Paper 96-1791, May 1996.

13. Ventres, C.S., Theobald, M.A., and Mark, W.D., "Turbofan Noise Generation, Volume 1: Analysis," NASA-CR 167951, July 1982.

14. Ventres, C.S., Theobald, M.A., and Mark, W.D., "Turbofan Noise Generation, Volume 2: Computer Programs," NASA-CR 167952, July 1982.

15. Meyer, H.D. and Envia, E., "Aeroacoustic Analysis of Turbofan Noise Generation," NASA-CR 4715, March 1996.

16. Philbrick, D.A. and Topol, D.A., "Development of a Fan Noise Design System, Part 1: System Design and Source Modeling," AIAA Paper 93-4415, October 1993.

17. Majjigi, R.K. and Gliebe, P.R., "Development of a Rotor/Wake Vortex Model," NASA-CR 174849 , Volume 1, June 1984.

18. Dalton, W.N., Elliott, D.B., and Nickols, K.L., "Design of a Low Speed Fan Stage for Noise Suppression," NASA-CR (No.TBD), June 1997.

19. Eversman, W. and Danda Roy, I., "Ducted Fan Acoustic Radiation including the Effects of Non- 
Uniform Mean Flow and Acoustic Treatment," AIAA Paper 93-4424, 1993.

20. Eversman, W., "Aft Fan Duct Acoustic Radiation," CEAS/AIAA 95-155, 1995.

21. Topol, D.A., "Development of a Fan Noise Design System, Part 2: Farfield Radiation and System Evaluation," AlAA 93-4416, 1993.

22. Nallasamy, M., "Computation of Noise Radiation from Fan Inlet and Aft Ducts," Journal of Aircraft, Vol. 43, No. 3, 1997, pp. 387-393.

23. Heidelberg, L.J., Hall, D.G., Bridges, J.E., and Nallasamy, M., "A Unique Ducted Fan Test Bed for Active Noise Control and Aeroacoustics Research," AlAA Paper 96-1740, May 1996 (also NASA-TM 107213).

24. Sutliff, D.L., Nallasamy, M., Heidelberg, L.J., and Elliott, D.M., "Baseline Acoustic Levels of the NASA Active Noise Control Fan Rig," AlAA96-1745, May 1996 (also NASA-TM 10721).

25. Woodward, R.P., Dittmar, J.H., Hall, D.G., and KeeBowling, B., "Background Noise Levels Measured in the NASA Lewis 9- by 15-Foot Low-Speed Wind Tunnel, AIAA Paper 95-0720 (also NASA-TM 106817).

\section{APPENDIX}

\section{Tone Power Level Comparisons}

In this appendix, tone power level comparisons for the 2BPF through 5BPF tones at approach, cutback and takeoff conditions are shown. The predicted in-duct power levels were calculated using the BBN/V072 code while the experimental levels were computed by integrating the 1 foot lossless directivities estimated from the measured 88inch sideline sound pressure levels. Using the same procedure, the corresponding broadband noise level in the neighborhood of each tone was also calculated to help with the analysis of the tone data.

The Figures A1 through A3 show the absolute tone power levels for the radial, swept-only and swept and leaned stators, respectively. In these figures, open bars represent predicted levels, darkly shaded bars the data, and lightly shaded bars the broadband levels. The trends with tone order, fan speed and stator configuration are somewhat mixed, but the following observations can be made. The theory over-predicts the measured levels for the low order tones especially for the radial stator. The opposite trend is true for the higher order tones particularly for the swept-only and swept and leaned stators. It should be noted that, in the under-predicted cases, the theoretical power level is generally below the measured broadband power level.

In the last three figures the predicted (open bars) and measured (darkly shaded bars) tone power level reductions are shown. In these figures, the broadbandcorrected theoretical reductions (lightly shaded bars) are also shown for comparison. In computing the broadbandcorrected theoretical reductions, the predicted levels themselves were used if they were above the broadband, and the broadband levels if the predicted theoretical levels were below the broadband level. Figure A4 shows the reductions due to swept-only stator (i.e. $P(30,0)-P(0,0)$ ), Figure $A 5$ the reductions due to swept and leaned stator (i.e., $P(30,-30)-P(0,0)$ ), and Figure A6 the reductions due to swept and leaned stator relative to the swept-only stator(i.e., $P(30,-30)-P(30,0)$ ). For nearly all combinations of tone, speed and configuration, the datatheory comparison is remarkably good when the broadband-corrected theoretical reductions are matched against the measured reductions. These comparisons are in accord with those shown for the SPL directivity comparisons in Section 3.2 of the report. 


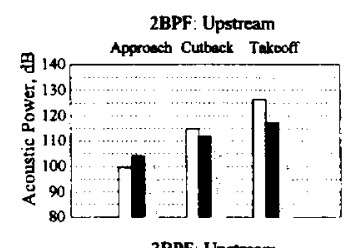

3BPF: Upstream

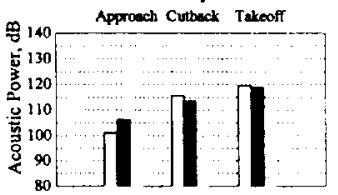

4BPF: Upstream

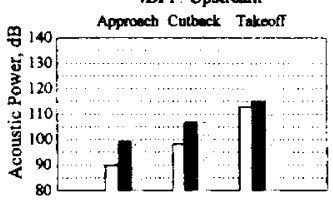

SBPF: Upstream

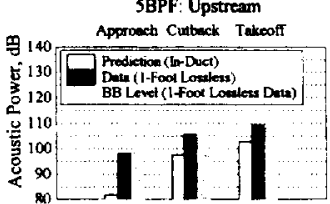

Figure A1. Comparison of measured and predicted tone power levels for the radial stator. Power level in the broadband at each tone is also shown.

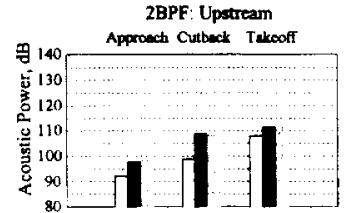

3BPF: Upatream

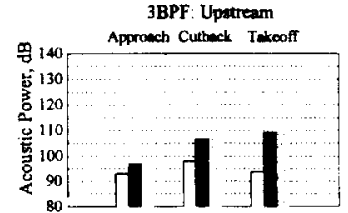

4BPF: Upstream

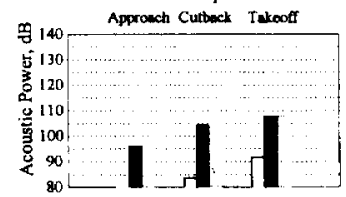

SBPF: Upatream

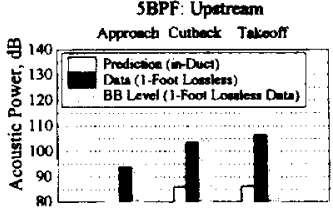

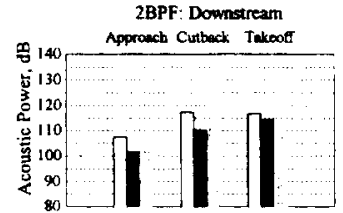

3BPF: Downstream

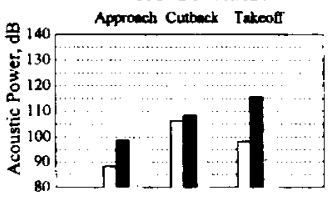

4BPF: Doxnstream

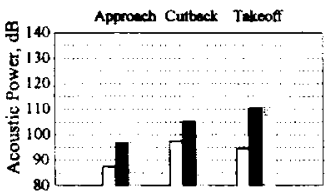

SBPF: Downstream

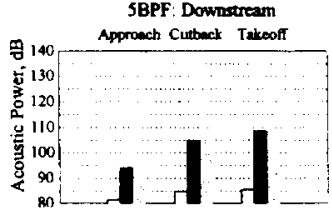

Figure A3. Comparison of measured and predicted tone power levels for the swept and leaned stator. Power level in the broadband at each tone is also shown.
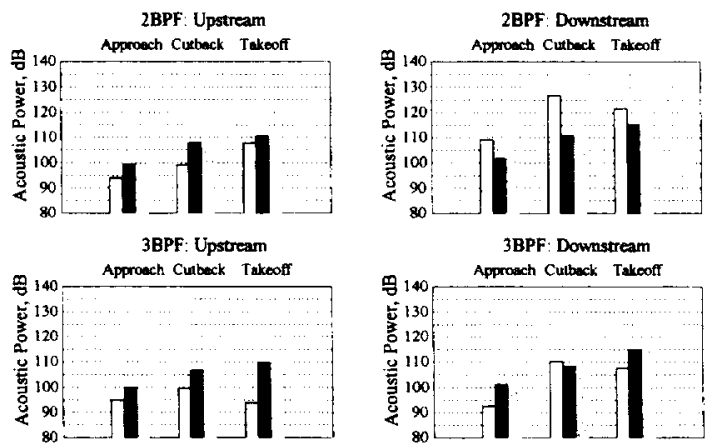

4BPF: Upstream

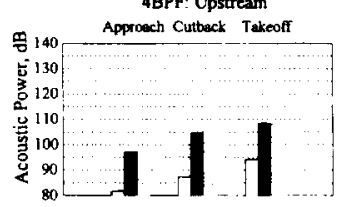

SBPF: Upstrean
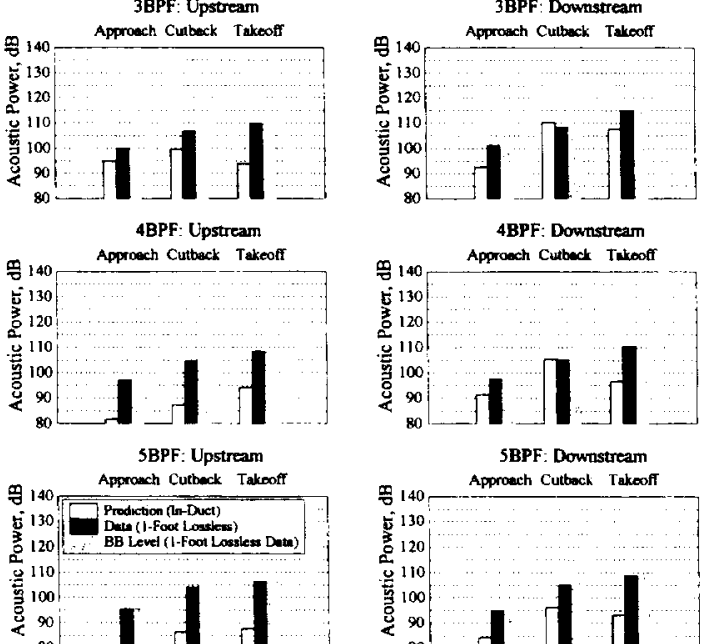

4BPF: Downstream

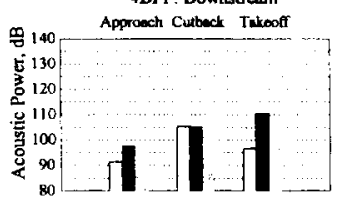

SBPF: Downstrean

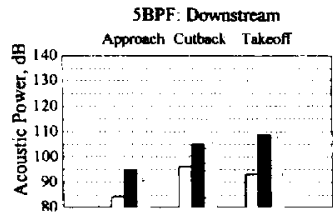

Figure A2. Comparison of measured and predicted tone power levels for the swept-only stator. Power level in the broadband at each tone is also shown.
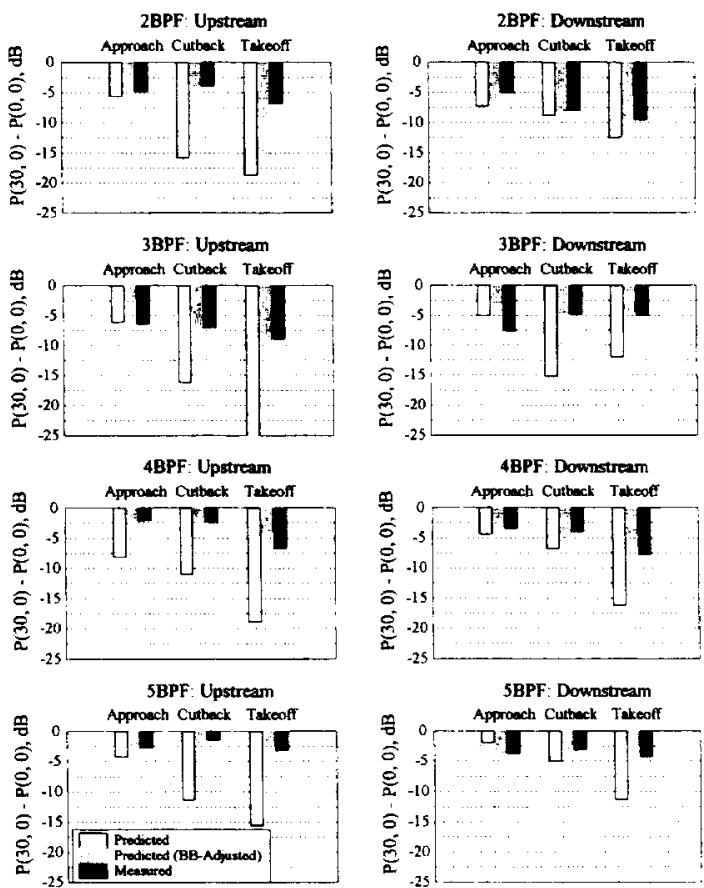

Figure A4. Measured and predicted tone power level reductions for the swept-only stator relative to the radial stator. Theoretical reductions based on broadband-corrected predicted levels are also shown. 

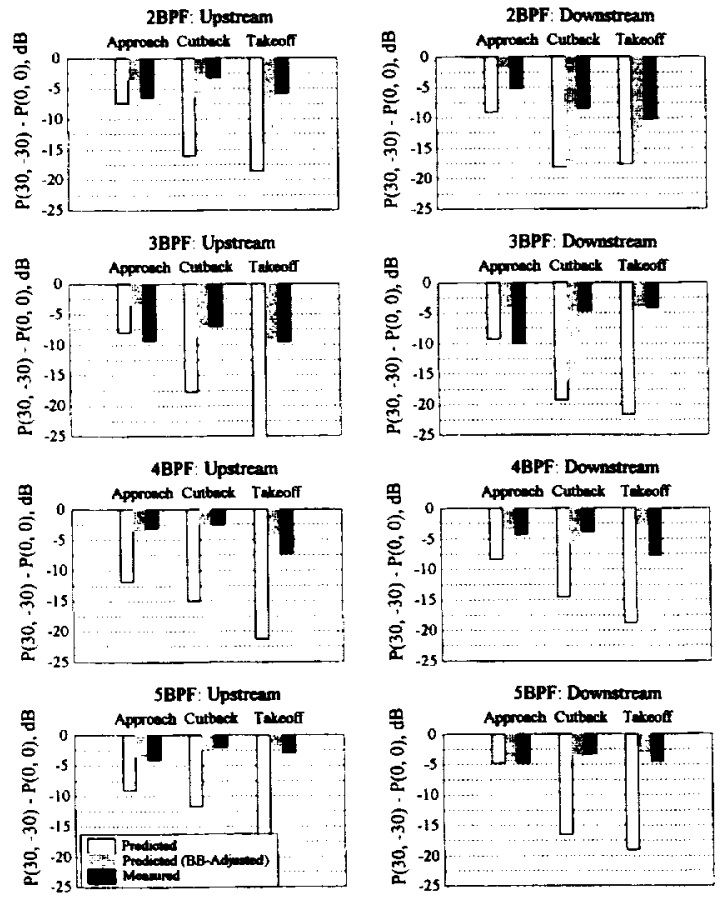

Figure A5. Measured and predicted tone power level reductions for the swept and leaned stator relative to the radial stator. Theoretical reductions based on broadbandcorrected predicted levels are also shown.
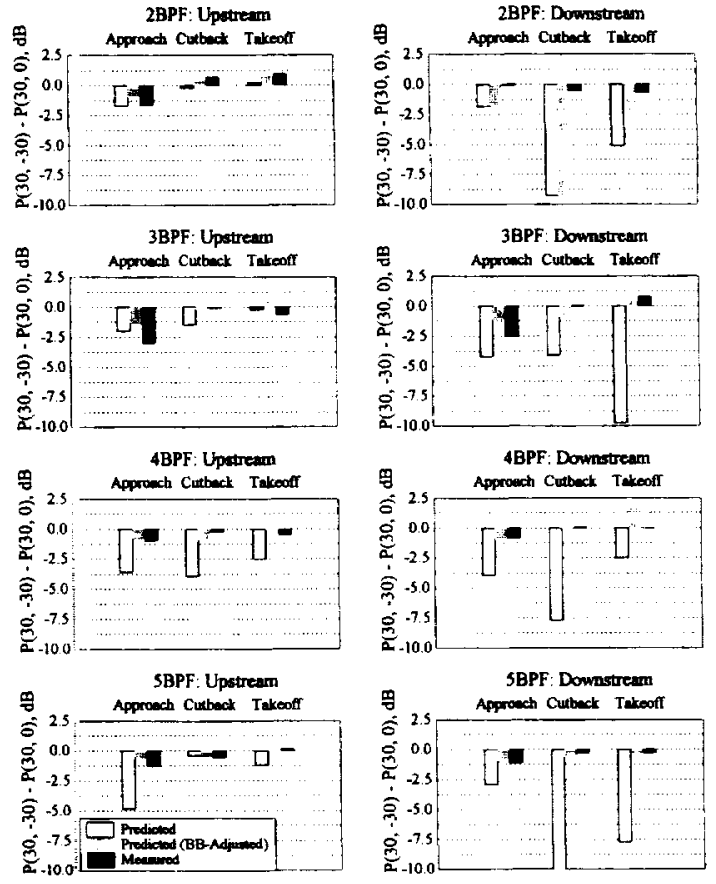

Figure A6. Measured and predicted tone power level reductions for the swept and leaned stator relative to the sweptonly stator. Theoretical reductions based on broadband-corrected predicted levels are also shown. 



\begin{tabular}{|c|c|c|c|c|}
\hline \multicolumn{3}{|c|}{ REPORT DOCUMENTATION PAGE } & \multicolumn{2}{|r|}{$\begin{array}{l}\text { Form Approved } \\
\text { OMB No. } 0704-0188\end{array}$} \\
\hline \multicolumn{5}{|c|}{ 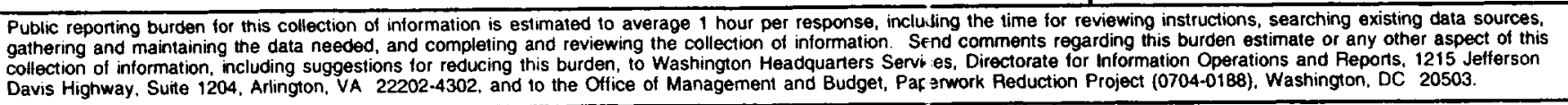 } \\
\hline 1. AGENCY USE ONLY (Leave blank) & $\begin{array}{r}\text { 2. REPOAT DATE } \\
\text { December } 1998 \\
\end{array}$ & \multicolumn{3}{|c|}{$\begin{array}{l}\text { 3. RE ORT TYPE AND DATES COVERED } \\
\text { Technical Memorandum }\end{array}$} \\
\hline \multicolumn{3}{|c|}{$\begin{array}{l}\text { 4. TITLE AND SUBTITLE } \\
\text { Design Selection and Analysis of a Swept and Leaned Stator Concept }\end{array}$} & \multirow{2}{*}{\multicolumn{2}{|c|}{$\begin{array}{l}\text { 5. FUNDING NUMBERS } \\
\text { WU-538-03-11-00 }\end{array}$}} \\
\hline \multicolumn{3}{|c|}{$\begin{array}{l}\text { 6. AUTHOR(S) } \\
\text { Edmane Envia and M. Nallasamy }\end{array}$} & & \\
\hline \multicolumn{3}{|c|}{$\begin{array}{l}\text { 7. PEFFORMING ORGANIZATION NAME(S) AND ADDRESS(ES) } \\
\text { National Aeronautics and Space Administration } \\
\text { Lewis Research Center } \\
\text { Cleveland, Ohio } 44135-3191\end{array}$} & \multicolumn{2}{|c|}{$\begin{array}{l}\text { 8. PERFORMING ORGANIZATION } \\
\text { REPORT NUMBER } \\
\text { E-11383 }\end{array}$} \\
\hline \multicolumn{3}{|c|}{$\begin{array}{l}\text { 9. SPONSORING/MONITORING AGENCY NAME(S) AND ADDRESS(ES) } \\
\text { National Aeronautics and Space Administration } \\
\text { Washington, DC 20546-0001 }\end{array}$} & \multicolumn{2}{|c|}{$\begin{array}{l}\text { 10. SPONSORING/MONITORING } \\
\text { AGENCY REPORT NUMBER } \\
\text { NASA TM-1998-208662 }\end{array}$} \\
\hline \multicolumn{5}{|c|}{$\begin{array}{l}\text { 11. SUPPLEMENTARY NOTES } \\
\text { Edmane Envia, NASA Lewis Research Center and M. Nallasamy, NYMA, Inc., } 2001 \text { Aerospace Parkway, Brook Park, } \\
\text { Ohio 44142, presently at Dynacs Engineering Corporation, 2001 Ae:ospace Parkway, Brook Park, Ohio } 44142 . \\
\text { Responsible person,. Edmane Envia, organization code 5940, (216) 433-8956. }\end{array}$} \\
\hline \multicolumn{3}{|c|}{$\begin{array}{l}\text { 12a. DISTRIBUTIONAVAILABILITY STATEMENT } \\
\text { Unclassified - Unlimited } \\
\text { Subject Category: } 71 \\
\text { This publication is available from the NASA Center for AeroSpace Information, (301) 621-0390. }\end{array}$} & \multicolumn{2}{|c|}{ 12b. DISTRIBUTION CODE } \\
\hline \multicolumn{5}{|l|}{$\begin{array}{l}\text { stator interaction tone no } \\
\text { principal factor in detern } \\
\text { by the stator vanes and } \\
\text { intersections reduces noi } \\
\text { as to increase wake inter } \\
\text { that puts the vane tip do } \\
\text { comparison of the predic } \\
\text { these comparisons show } \\
\text { well as quantitative, with } \\
\text { more, the results also de }\end{array}$} \\
\hline \multirow{3}{*}{\multicolumn{2}{|c|}{$\begin{array}{l}\text { 14. SUBJECT TERMS } \\
\text { Acoustics }\end{array}$}} & & & $\begin{array}{l}\text { 15. NUMBER OF PAGES } \\
23\end{array}$ \\
\hline & & & & 16. PAICE CODE \\
\hline & & & & \begin{tabular}{|c}
$\mathrm{A} 03$ \\
20. LMITATION OFF ABSTRACT
\end{tabular} \\
\hline $\begin{array}{l}\text { 17. SECURITY CLASSIFICATION } \\
\text { OF REPORT }\end{array}$ & $\begin{array}{l}\text { 18. SECURITY CLASSIFICATION } \\
\text { OF THIS PAGE }\end{array}$ & $\begin{array}{l}\text { 19. SEC JRITY CLASSIFIC } \\
\text { OF ABSTRACT }\end{array}$ & ATION & 20. LIMITATION OF ABSTRACT \\
\hline Unclassified & Unclassified & Unclassified & & \\
\hline
\end{tabular}

